\title{
Lattice oxygen activity in ceria-praseodymia mixed oxides for soot oxidation in catalysed Gasoline Particle Filters
}

\author{
J.C. Martínez-Munuera, M. Zoccoli, J. Giménez-Mañogil and A. García-García* \\ MCMA Group, Department of Inorganic Chemistry and Institute of Materials. \\ University of Alicante. Carretera de Sant Vicent del Raspeig, s/n, 03690 Sant Vicent del \\ Raspeig, Alicante. SPAIN.
}

\begin{abstract}
Two series of ceria-praseodymia catalysts with varying composition have been systematically investigated in the oxidation of soot under inert atmosphere in order to find out its potential utilization in Gasoline Particulate Filters for GDI engines. The samples have been widely characterized by XRD, Raman spectroscopy, TEM, FESEM, XPS, $\mathrm{N}_{2}$ adsorption at $-196^{\circ} \mathrm{C}$ and $\mathrm{O}_{2}$-TPD. The praseodymium incorporation onto the ceria enhances the oxygen mobility in the subsurface/bulk of the sample favoring higher $\mathrm{O}_{2}$ released amounts under inert atmosphere. The intermediate compositions can promote more accentuated $\mathrm{O}_{2}$ emissions at moderate temperatures (up to $500^{\circ} \mathrm{C}$ ). The efficiency of the own active oxygen species released from the catalyst to oxidize soot under inert atmosphere, even under loose contact mode, has been well demonstrated. The pathways of the mechanism taking place seem to be dependent on the temperature and mainly on the type of contact among soot and catalyst. Under loose contact conditions and lowmedium temperatures, the $\mathrm{O}_{2}$ freshly emitted from the catalyst can oxidize soot more efficiently than a diluted $\mathrm{O}_{2}$-gas stream. Conversely, under more severe conditions (higher temperature or tight contact conditions), the soot acts as a "driving force" and the own lattice oxygen species can be transferred directly towards soot surface in an efficient way.
\end{abstract}

Keywords: soot oxidation; Gasoline Particulate Filter (GPF); ceria-praseodymia mixed oxides; lattice oxygen.

*Corresponding author.Tel.: +34 965909419; e-mail: a.garcia@ua.es Fax: +34 965903454 


\section{Introduction}

By 2020, the European Union has imposed a $\mathrm{CO}_{2}$ emission target of $95 \mathrm{~g} / \mathrm{km}$ for passenger cars [1,2]. Gasoline Direct Injection (GDI) engines technology has the potential of substantially improving the overall fuel economy and thus, reducing $\mathrm{CO}_{2}$ levels [3]. Therefore, it is well-known that the gasoline direct injection (GDI) technology provides higher thermal efficiency and more power output than the traditional port fuel injection (PFI) and multi point injection (MPI) spark ignition [4-6]. As a consequence of these facts, the GDI technology is expanding rapidly and has recently become of great interest to many automotive Original Equipment Manufacturers (OEMs) [3,7,8]. GDI offers significant advantages over traditional engines in fuel economy, performance, drivability, and thus $\mathrm{CO}_{2}$ emissions $[6,9,10]$.

One downside of these advanced engines is their significantly higher particulate emissions compared to engines based on port fuel injection technologies. This concerns both particulate matter $(\mathrm{PM})$ and particulate number (PN) emissions [11], (especially the smaller particles), than the traditional PFI engines under all engine operating conditions, because of some different factors like the differences in fuel injection, mixture preparation, and the lean and stratified operation capability $[10,12,13]$. These small particles (mostly below $100 \mathrm{~nm}$ in diameter) are present in large number in the untreated exhaust, but this amount corresponds only to a tiny fraction of the particulate matter weight. It was found that the vehicles equipped with GDI engines emitted roughly two orders (or much higher) of magnitude of the ultrafine particles (UFP) than the DPFequipped light-duty (LD) diesel vehicles and the PFI gasoline engines [8]. Therefore, the $\mathrm{PM}$ and PN emissions from GDI engines are of serious concern due to their carcinogenic character [14]. 
In order to respond to the health concerns regarding UFP, the European Union (EU) has approved the Euro VI/6 emission regulations, mandating both PM and PN on heavyduty (HD) diesel engines, LD diesel vehicles, as well as the LD vehicles equipped with GDI engines. A significant reduction of PN emissions from GDI engines is necessary, especially from present days onwards because a limit of $6.0 \times 10^{11}$ particles $/ \mathrm{km}$ has become mandatory [15-17].

In this context, Gasoline Particulate Filters (GPFs) are one potential technology path to address the Euro 6 particulate number regulation for vehicles powered by gasoline DI engines [11]. During vehicle operation, the particulates are trapped in the GPF and accumulate over time. More than $90 \%$ of the emitted particulate mass is soot, consisting primarily of elemental carbon and small fractions of hydrocarbons and ashes. The amount of soot in the filter can be diminished by oxidation at high temperatures under the presence of an oxidant (e.g. oxygen). Of special practical interest would be an understanding of the conditions which would enable a passive oxidation of the accumulated soot. However, gasoline engines are typically operated in stoichiometric conditions; hence under normal operating, the $\mathrm{NO}_{2}$, which is very effective in diesel applications, is reduced at very low levels over the upstream three-way catalyst (TWC) and there is also no appreciable oxygen as oxidant, because it is only available during fuel cuts [18]. Taking into account this scenario, many authors consider obvious that a catalysed gasoline particulate filter might be suitable and a cost-efficient solution to deal with the recently implemented Euro 6c legislation [15]. Nevertheless, these very different working conditions, compared with those in traditional diesel engines, might lead conventional diesel soot oxidation catalysts (e.g. based on platinum) to be quite ineffective [19]. 
Based on some previous studies of these authors [20,21], these demanding exhaust conditions may provide opportunities for ceria-based materials, with well-demonstrated deep oxidation activity, promoted oxygen storage/redox behaviour and presenting a very high activity for soot combustion even under a $\mathrm{O}_{2}$-only stream [21-23]. More recently, the authors reported a high ability of some ceria-praseodymia formulations as "deliverers" of oxygen, even under inert atmosphere [24].

The corresponding mixed oxides, $\mathrm{Ce}_{1-\mathrm{x}} \mathrm{Pr}_{\mathrm{x}} \mathrm{O}_{2-\delta}$, can undergo more oxygen exchange at a lower temperature than pure ceria and it is also known that the Ce-Pr-O compositions are more promising than the trivalent rare-earth substituted ceria formulations [24-26]. It could be assumed that Pr-containing mixed oxides should exhibit intermediate and close to optimal combination of capacity, stability and reactivity with respect to reversible oxygen evolution/uptake, but in catalytic oxidation reactions with practical application not all the reactive oxygen can be available and the establishment of structural-redoxcatalytic performances relationships under representative reaction conditions, mainly if they are very demanding, could be of special interest [27]. Therefore, the combination of all these features may result in very promising catalysts for cGPF, but a detailed study under conditions relatively close (simulated) to those encountered in GDI exhaust, is needed.

The present work is devoted to synthesizing and characterizing two series of $\mathrm{Ce}_{1}$ ${ }_{x} \mathrm{Pr}_{\mathrm{x}} \mathrm{O}_{2-\delta}$ mixed oxides, prepared from two simple synthesis procedures, ranging the whole ratio of compositions (in terms of $\mathrm{Ce} / \mathrm{Pr}$ ratio), to perform a detailed characterization analysis, trying to find out correlations among all the physicochemical features and activity towards soot combustion under $\mathrm{NO}_{\mathrm{x}} / \mathrm{O}_{2}$-free atmospheres. For this purpose, one of the main goals of the present study is the detailed analysis of the $\mathrm{O}_{2}$-emission profiles by the catalysts under inert atmosphere and to prove that the freshly-emitted $\mathrm{O}_{2}$ is very 
reactive to combust soot even under loose contact mode. The correlations between catalytic performances (both under loose and tight contact) obtained and the structural and redox properties are explored and connected to the catalysts' composition and method of preparation. Finally, possible reasons for high activity of these sets of samples for soot oxidation have been proposed and discussed to establish mechanistic implications in the framework of different degrees of contact soot/catalyst.

\section{Materials and methods}

\subsection{Catalyst preparation.}

Two sets of ceria-praseodymia mixed oxides, ranging the whole range of compositions $\left(\mathrm{Ce}_{1-\mathrm{x}} \mathrm{Pr}_{\mathrm{x}} \mathrm{O}_{2}, x=0.2,0.3,0.4,0.5,0.6,0.7,0.8,0.9,1\right)$ were prepared following two simple procedures. The first one is a classic co-precipitation method, using $\mathrm{Ce}\left(\mathrm{NO}_{3}\right)_{3} \cdot 6 \mathrm{H}_{2} \mathrm{O}$ (supplied by Aldrich, 99\%) and $\mathrm{Pr}\left(\mathrm{NO}_{3}\right)_{3} \cdot 6 \mathrm{H}_{2} \mathrm{O}$ (supplied by Sigma Aldrich, 99.9\%) as precursors. The required amounts of each precursor were dissolved in water under mild stirring conditions. Upon complete dissolution, ammonia was added dropwise until the precipitation was complete $(\mathrm{pH} \sim 9)$. The accumulated mixed-oxide/hydroxide solid was recovered by filtration. It was then dried in an oven at $110{ }^{\circ} \mathrm{C}$ for $24 \mathrm{~h}$, and subsequently calcined at $500{ }^{\circ} \mathrm{C}$ for $1 \mathrm{~h}$ in static air. Both pure cerium oxide and praseodymium oxide were also prepared, for comparative purposes, by adopting the same precipitation method. A previous study, where some of these compositions were prepared by the same co-precipitation method, determined that the actual Ce/Pr compositions obtained after the calcination step were very close to those intended to obtain [25]. 
The second preparation method consists of the direct calcination of the nitrate precursors. For this purpose, the required amounts of every precursor (in order to reach the different $\mathrm{Ce} / \mathrm{Pr}$ molar compositions in the mixed oxides obtained) were intimately mixed in a mortar and subsequently calcined at $500{ }^{\circ} \mathrm{C}$ for $1 \mathrm{~h}$ in static air as well. Pure oxides were synthesised in the same way. The nomenclature of the samples includes the molar composition of the mixed oxide $\left(\mathrm{Ce}_{1-\mathrm{x}} \mathrm{Pr}_{\mathrm{x}} \mathrm{O}_{2}\right)$ followed by "CP" which refers to the method of Co-Precipitation or "DC" which refers to the method of Direct Calcination of the nitrate precursors.

\subsection{Catalyst characterization.}

The specific surface areas of the samples were determined by the BET method. $\mathrm{N}_{2}$ adsorption-desorption isotherms were obtained at $-196^{\circ} \mathrm{C}$ in an automatic volumetric system (Autosorb-6B from Quantachrome) after degassing the samples at $250^{\circ} \mathrm{C}$ for $4 \mathrm{~h}$. The specific pore volume was calculated from the desorption branches of the isotherms at $\mathrm{P} / \mathrm{P}_{0}=0.98$ following the criteria used by Moretti et al. [28]. The pore size distribution of the materials was analysed using the Barrett-Joyner-Halenda (BJH) method.

Powder XRD patterns were recorded in a Bruker D8 advance diffractometer, using the $\mathrm{CuK} \alpha$ radiation $(\lambda=0.15406 \mathrm{~nm})$. Diffractograms were recorded between $20^{\circ}$ and $65^{\circ}(2 \theta)$ with a step size of $0.05^{\circ}$ and measuring for $3 \mathrm{~s}$ at each step. Indexation was performed by means of specific software (EVA) and the calculation of the average crystal sizes was carried out using the Scherrer's equation.

Raman spectra were performed in a LabRam Jobin Ivon Horiba Raman Spectrometer with a variable power He-Ne laser source $(632.8 \mathrm{~nm})$ and $1 \mathrm{~mW}$ laser power, using a confocal microscope. The spectra were acquired after 2 scans of $200 \mathrm{~s}$ each one. 
XPS spectra were obtained using a K-Alpha spectrophotometer (ThermoScientific), with a high-resolution monochromator. It comprises a source of electrons and ions for automated load compensation. The X-ray radiation source comprises an $\mathrm{Al}$ anode $(1486.6 \mathrm{eV})$. The pressure of the analysis chamber was kept at $5 \cdot 10^{-9} \mathrm{mbar}$ and was kept working with the detector in constant energy mode with a pass energy of $200 \mathrm{eV}$ for the survey spectrum and $50 \mathrm{eV}$ for the sweep in each individual region. The binding energy was adjusted using the $\mathrm{C} 1 \mathrm{~s}$ transition, appearing at $284.6 \mathrm{eV}$. Binding energy values measured are accurate to $\pm 0.2 \mathrm{eV}$. The values of binding energy and kinetic energy were adjusted with the Peak-Fit software of the spectrophotometer.

The Ce-3d and Pr-3d (along with C-1s, and O-1s regions) were used in order to determine the surface composition of the studied catalysts. The proportion of $\mathrm{Ce}^{3+}$ cations with regard to the total cerium on the surface was calculated as described by Laachir et al. [29] and the $\operatorname{Pr}^{3+}(\%)$, with regard to total praseodymium, was estimated as proposed by Borchet et al. [30].

The morphology of the samples was analyzed using a ZEISS Merlin VP Compact Field Emission Scanning Electron Microscopy (FESEM) equipment. The corresponding resolution is $0.8 \mathrm{~nm}$ at $15 \mathrm{kV}$ and $1.6 \mathrm{~nm}$ at $1 \mathrm{kV}$, respectively. A JEOL JEM-2010 microscope was used as well to obtain TEM images of the catalysts. Few droplets of an ultrasonically dispersed suspension of each catalyst in ethanol were placed in a grid and dried at ambient conditions for TEM characterisation.

\subsection{Temperature-Programmed Desorption under inert atmosphere (measurement of} $\mathrm{O}_{2}$ evolution). 
The reaction products, mainly the $\mathrm{O}_{2}$ profiles evolution, during TemperatureProgrammed Desorption under inert atmosphere were analysed by using a simultaneous TG-DTA coupled to a mass spectrometer (TG-DTA-MS), for all the fresh samples. The TG-DTA equipment is a SDT Q600 Simultaneous from TA Instruments, capable of working between room temperature and $1500^{\circ} \mathrm{C}$. The mass spectrometer is a Balzers BSC 200 from Thermostar. The experiments were performed with $20 \mathrm{mg}$ of sample, under $100 \mathrm{ml} / \mathrm{min}$ of inert He atmosphere, heating under programmed temperature at $10^{\circ} \mathrm{C} / \mathrm{min}$ from $150^{\circ} \mathrm{C}$ to $950^{\circ} \mathrm{C}$. Before starting the experiments, the samples were kept at $150^{\circ} \mathrm{C}$ for one hour under He flow. The quantification of the oxygen signal by MS was conducted by using copper(II) oxide $(\mathrm{CuO})$ as calibration standard. In the case of $\mathrm{CuO}$, the stoichiometric reaction taking place is the following:

$$
2 \mathrm{CuO} \rightarrow \mathrm{Cu}_{2} \mathrm{O}+1 / 2 \mathrm{O}_{2}
$$

After verifying that the TG weight loss matched the entire $\mathrm{O}_{2}$ evolution expected by $\mathrm{CuO}$ reduction to $\mathrm{Cu}_{2} \mathrm{O}$ [31], the $\mathrm{MS}$ signal integration value $(\mathrm{m} / \mathrm{z}$ 32) was used as calibration for $\mathrm{O}_{2}$. This allowed us to obtain an $\mathrm{O}_{2}$ emission profile (expressed as $\mu$ mol $\left.\mathrm{O}_{2} / \mathrm{g}_{\mathrm{cat}} \cdot \mathrm{s}\right)$. As a consequence of the expected population of vacancies created by $\mathrm{O}_{2}$ release from the catalysts, $\delta$ parameter $\left(\mathrm{Ce}_{1-\mathrm{x}} \mathrm{Pr}_{\mathrm{x}} \mathrm{O}_{2-\delta}\right)$, after TPD, was estimated.

\subsection{Soot combustion tests.}

As previously reported, Printex-U can be considered a reasonable substitute for GDI soot $[18,32,33]$, since they share similar morphologies and oxidation behaviour and it was used as the model soot in this study. Two types of soot combustion tests were conducted, under loose and tight contact conditions, following this protocol: 
- Temperature-Programmed Oxidation (TPO) at heating rate of $10^{\circ} \mathrm{C} / \mathrm{min}$ from room temperature up to $950^{\circ} \mathrm{C}(100 \mathrm{ml} / \mathrm{min})$, under inert atmosphere, where the soot oxidation takes place with the own oxygen delivered or transferred from the catalyst to the soot surface. These tests were carried out in the same apparatus described above. Samples were pre-treated under He up to $150^{\circ} \mathrm{C}$ for 1 hour. The catalyst/soot ratio employed was 20/1 and the mixing mode used was the so-called loose contact [34], more representative of the conditions achieved on a cGPF. Although loose contact conditions are clearly closer to real situations, tight contact mode is helpful to reflect the intrinsic characteristics of the catalysts and assure a more homogeneous and reproducible mixture. For this reason, representative catalysts were studied as well by mixing the soot and the respective catalyst powder, under intimate contact in an agate mortar, for $10 \mathrm{~min}$. to improve the soot/catalyst agglomerate contact [35]. The $\mathrm{O}_{2}$ evolving from the catalysts and the soot combustion products $\left(\mathrm{CO}_{2}\right.$ and $\left.\mathrm{CO}\right)$ were continuously recorded with $\mathrm{MS}$ analysis.

\section{Results and discussion}

\subsection{Structural, textural and morphological characterization.}

Figure 1 shows the X-Ray diffractograms of catalysts prepared by the coprecipitacion route (Figure 1a) and the direct calcination route (Figure 1b), together with the reference patterns of pure phases $\left(\mathrm{CeO}_{2}, \mathrm{PrO}_{2}, \operatorname{PrO}_{1.83}\right.$ and $\left.\operatorname{Pr}_{6} \mathrm{O}_{11}\right)$. According to this technique, all the ceria-praseodymia mixed oxides obtained exhibit single cubic fluoritetype structure [36], and in principle, no other segregated phases are evidenced. In fact, both cerium dioxide and praseodymium dioxide are known to present cubic fluorite-type 
structure. Since the ionic radius of $\operatorname{Pr}^{4+}$ is very close to that of $\mathrm{Ce}^{4+}(0.96$ versus $0.97 \AA$, respectively) cerium and praseodymium oxides could form solid solutions. However, $\operatorname{Pr}$ can form several stoichiometric and non-stoichiometric sub-oxides with formula $\mathrm{PrO}_{\mathrm{x}}$, where $x \leq 2$, which would present diffraction patterns only slightly different to that of fluorite ceria $[30,37]$. This suggests that the variation trends of the lattice parameter $a$ in the samples studied could obey different reasons: the degree of cation insertion and its oxidation state [26,37]. In this sense, the lattice parameter $a$ is plotted against $x$ (praseodymium content) in Figure 2. The results show that the values of $a$ are clearly dependent on the preparation method employed [37], being higher for those catalysts obtained from the co-precipitation method, especially at high cerium compositions, but showing the same values for $\mathrm{Ce}_{0.1} \operatorname{Pr}_{0.9} \mathrm{O}_{2}$ and pure praseodymia formulations. The dotted lines in Figure 2 are based on Vegard's rule and give a theoretical estimation of $a$ as a function of $x$ [38]. The increasing dotted line provides the theoretical results from Vegard's rule for the formation of a solid solution between $\mathrm{CeO}_{2}$ and $\mathrm{PrO}_{1.83}$ (as reflected in Figure 2). This is motivated because the trivalent ions are larger in size $\left(\operatorname{Pr}^{3+}=0.1126\right.$ and $\mathrm{Ce}^{3+}=0.1143 \mathrm{~nm}$ in eightfold co-ordination) compared to the tetravalent ions and hence a significant increase in the cell parameter is expected, corresponding to the amount of trivalent ions present in the lattice [39]. The variation of cell parameter with $x$ for $\mathrm{CeO}_{2}$ $\mathrm{PrO}_{1.83}$ system can be given below:

$$
a=0.0059 x+0.5411 \mathrm{~nm}
$$

The second dotted line, with negative slope, provides the linear expression between $a$ and $\mathrm{x}$, where $\mathrm{Pr}^{4+}$ substitutes for $\mathrm{Ce}^{4+}$ in the lattice sites:

$$
a=-0.002 x+0.5411 \mathrm{~nm}
$$


The trends exhibited by the co-precipitated samples show that, according to the results reported by Rajendran et al. [37]. For $x$ values from 0 to 0.3 , the cell parameter increases following the trend expected by eq. (2), indicating the formation of solid solution $\left(\mathrm{CeO}_{2}\right.$ $\mathrm{PrO}_{1.83}$ ). However, when $x$ takes values between 0.4 and 0.8 , a gradual and smooth cell parameter decrease is observed (opposite to the trend predicted by Vegard's law), suggesting that Pr is not inserting into the lattice efficiently for these compositions. For $\mathrm{Ce}_{0.1} \mathrm{Pr}_{0.9} \mathrm{O}_{2}-\mathrm{CP}$ and $\mathrm{PrO}_{2}-\mathrm{CP}$ catalysts, a dramatic increase in the cell parameter is observed. $\mathrm{PrO}_{2}-\mathrm{CP}$ shows a parameter very close to Vegard's value. Actually, the corresponding XRD diffractogram matches the diffraction patterns of $\operatorname{PrO}_{1.83}$ and $\operatorname{Pr}_{6} \mathrm{O}_{11}$ much better than that of $\mathrm{PrO}_{2}$ composition, indicating a significant degree of oxygen deficiency in this catalyst $[39,40]$.

As commented above, the $a$ values are clearly lower for the ceria-praseodymia mixed oxides prepared by the direct calcination method, thus suggesting a lower degree of cation insertion and/or lower contribution of $\operatorname{Pr}^{3+}$ species. A point of inflection is clearly seen from $\mathrm{Ce}_{0.3} \operatorname{Pr}_{0.7} \mathrm{O}_{2}$-DC composition on, where the lattice parameter becomes more and more similar to that of the counterpart samples prepared by the co-precipitation route. Finally, at the highest praseodymium contents, values determined from both series of samples converge, providing evidences of higher presence of $\operatorname{Pr}^{3+}$ cation as becoming closer to the pure praseodymia formulation.

The most relevant feature that distinguishes the XRD diffraction profiles obtained from both series of samples is that wider peaks are shown by catalysts prepared from the co-precipitation method, which has been mostly attributed to lower average crystal size, even though the existence of different domains at nano-scale level cannot be excluded due to the diffraction peaks of the several phases involved appear at very close $2 \theta$ values [26]. Assuming this premise, the average crystal sizes were obtained from the width of 
the (111) and (220) reflections by means of the Scherrer's equation. The results are listed in Table 1, revealing higher average crystal sizes for the catalysts prepared by the direct calcination method with regard to the co-precipitation method, whatever the composition analyzed. For the former, the sizes range from 9.8 to $12.3 \mathrm{~nm}$ and for the latter from 7 to $9 \mathrm{~nm}$. No clear trends with increasing praseodymium content are observed in agreement with some results reported by other authors [26]. The relative minimum values are observed at intermediate compositions $\left(\mathrm{Ce}_{0.5} \mathrm{Pr}_{0.5} \mathrm{O}_{2}-\mathrm{DC}\right.$ and $\mathrm{Ce}_{0.4} \mathrm{Pr}_{0.6} \mathrm{O}_{2}-\mathrm{CP}$, respectively). The values of crystallite size do not follow any clear trend with the BET surface areas, whatever the method considered. The surface area values range from 10 to $70 \mathrm{~m}^{2} / \mathrm{g}$ (CP method) and from 6 to $47 \mathrm{~m}^{2} / \mathrm{g}$ (DC method), respectively, as illustrated in Figure $3 \mathrm{a}$, where the areas are represented as a function of $\operatorname{Pr}$ content, showing very different patterns on their both representations.

In order to go deeper into the textural characterization, the porous volume parameter (determined by means of $\mathrm{N}_{2}$ isotherms data, as explained in the experimental section), was plotted versus praseodymium loading (Figure $3 \mathrm{~b}$ ). The pore volume values tend to decreasing values for the direct calcination method, showing different trend than that exhibited by the corresponding BET surface area representation. Conversely, similar trends are observed for co-precipitated catalysts concerning BET surface areas and pore volumes plots.

The pore size distribution of each catalyst was evaluated from $\mathrm{N}_{2}$ desorption isotherms. Figures $4 \mathrm{a}$ and $4 \mathrm{~b}$ illustrate that an increase in Pr induces different changes in the pore size distribution for every preparation method analysed. For the direct calcination method a progressive and gradual decrease in mesopore contribution is dramatically seen with the praseodymium content. Additionally, a minor contribution at lower pore size (centred at $6 \mathrm{~nm}$ ) becomes predominant at high dopant content in the mixed oxides. $\mathrm{PrO}_{2}$ - 
DC presents nearly a flat profile, explaining the low value in pore volume and in BET surface area.

Conversely, $\mathrm{PrO}_{2}-\mathrm{CP}$ presents an accentuated mesoporosity with a broad pore size distribution, and similar features than those exhibited by $\mathrm{Ce}_{0.8} \operatorname{Pr}_{0.2} \mathrm{O}_{2}-\mathrm{DC}$ and $\mathrm{Ce}_{0.7} \mathrm{Pr}_{0.3} \mathrm{O}_{2}$-DC, as comparative examples. A sharp contribution centred at 3-4 nm appears for the mixed oxides, with a maximum value for the $\mathrm{Ce}_{0.6} \operatorname{Pr}_{0.4} \mathrm{O}_{2}-\mathrm{CP}$ catalyst.

The results reveal the following findings: i) very different trends in textural properties with the praseodymium content depending on the preparation method analysed and ii) the significance in this context of analysing the pore size distribution since both $\mathrm{Ce}_{0.6} \operatorname{Pr}_{0.4} \mathrm{O}_{2}$ compositions present very similar BET surface areas (38 and $40 \mathrm{~m}^{2} / \mathrm{g}$, respectively) but very different pore size distributions, as a representative example.

The discussion of the results has been focused on the textural and structural features so far, but with the reported data, it is not clear if there are only important differences in porosity in the samples or if the morphological features are different as well considering catalysts prepared from one procedure or the other one. Previous data were reported [41, 42] about the fact that the varied catalyst morphologies and pore structures can lead to different catalyst-soot contact conditions. This would have an impact on soot combustion activity. Some experimental evidences obtained from FESEM and TEM analysis on representative catalysts alone and from FESEM under both modes of contact with the soot particles, were shown on Figs. S1 and S2 (see the Supplementary Information).

The XRD results are well complemented by the Raman study. Raman spectra of both sets of samples are compiled in Figure 5a (catalysts prepared from the direct calcination method) and Figure 5b (catalysts prepared from the co-precipitation method). 
The Raman spectra of fresh ceria (not shown) prepared from the same cerium precursor and under the same experimental conditions presented the $F_{2 g}$ band at $464 \mathrm{~cm}^{-}$ ${ }^{1}$ characteristic of this material, which can be assigned to a symmetric breathing mode of the oxygen ions coordinating the tetravalent cations $[43,44]$. For the different oxides prepared for this study, this mode is progressively (but not in a gradual and proportional trend) red-shifted around $20.4 \mathrm{~cm}^{-1}$ (CP-method) and $20.5 \mathrm{~cm}^{-1}$ (DC-method) from $\mathrm{Ce}_{0.8} \mathrm{Pr}_{0.2} \mathrm{O}_{2}$ to $\mathrm{PrO}_{2}$ composition, indicating a decrease in the bond strength. This decrease can be caused by the existence of the trivalent cation (rather being $\operatorname{Pr}^{3+}$ than $\left.\mathrm{Ce}^{3+}\right)$, i.e. a weaker force constant of the corresponding cation-anion bonds. This interpretation is also supported by the mode observed at a wavenumber of around 570 $\mathrm{cm}^{-1}$, which is assigned to a defect mode caused by oxygen vacancies according to literature $[39,43,45-47]$. The relatively high intensity of this mode under atmospheric conditions suggests the existence of reduced cations (rather being $\operatorname{Pr}^{3+}$ than $\mathrm{Ce}^{3+}$ ). An additional mode at around $195 \mathrm{~cm}^{-1}$, whose changing trend can be correlated to that of the band at $570 \mathrm{~cm}^{-1}$, can be attributed to the other asymmetric vibration caused by the formation of oxygen vacancies [47]. The $F_{2 g}$ peak intensity gradually decreases with the Pr content due to a possible deformation of the lattice, affecting oxygen breathing. Actually, McBride et al. [43] reported that the Raman mode of $\mathrm{Ce}_{1-\mathrm{x}} \mathrm{RE}_{\mathrm{x}} \mathrm{O}_{2-\mathrm{y}}$ solid solutions becomes asymmetric with the presence of a long low-frequency tail as the $x$ value increases and an additional band at about $570 \mathrm{~cm}^{-1}$ on the high frequency side of the band. This asymmetry could affect the $F_{2 g}$ band position and the FWHM parameter. This could explain that the trend concerning the displacement of the $F_{2 g}$ mode is not proportional with the Pr content, even though a clear red-shift is observed for the two preparation methods, as seen on Table 1. Another possible argument could be related to 
the degree of Pr insertion, which varies depending on the Pr loading and the preparation method.

Additionally, for those compounds that become more coloured (as the case of those obtained from enhancing more and more the Pr loading), increased optical absorption has the effect of reducing the observed intensity of all the Raman peaks, making the analysis difficult. In order to shed light on this fact, Figure 6 shows the relationship of the $I_{560} / I_{F 2 g}$ ratio with the Pr content, obtained from the normalized spectra. This ratio can be considered an indicator of the abundance of the oxygen vacancies caused by the substitution of $\mathrm{Ce}$ atoms by $\mathrm{Pr}$ atoms in the mixed oxides [48]. Different trends can be seen with the preparation method and the range of Pr content investigated. Firstly, it can be seen that for a fixed composition the values do not match, with the exception of pure praseodymia, in agreement with other structural differences shown by the samples, such as cell parameter values and average crystal size. Another interesting finding is that paying attention to the direct calcination series, a clear inflection point is seen in its representation at an intermediate composition. The $\mathrm{I}_{570} / \mathrm{I}_{\mathrm{F} 2 \mathrm{~g}}$ values increase linearly with the Pr content on both sides of the representation, (but with different slopes). Luo et al. and Guo et al. $[48,49]$ reported that if the distribution of $\mathrm{Ce}$ and $\mathrm{Pr}$ in the mixed-oxides particles was uniform, there should not be any inflection point in the mentioned relationship and therefore, it should be considered that the composition of $\mathrm{Ce}_{1-\mathrm{x}} \mathrm{Pr}_{\mathrm{x}} \mathrm{O}_{2-\delta}$ mixed oxide particles in the surface shell and the bulk region might be different.

XPS analysis provided enough and consistent evidences in order to clarify possible differences in surface and bulk compositions of the mixed oxides' particles. Table 2 lists some representative parameters obtained from this XPS analysis, and additional information is provided on Supplementary Information. 
The $\mathrm{Ce} / \mathrm{Pr}$ surface atomic ratios for the ceria-praseodymia samples were always lower than the corresponding nominal values, (with the only exception of the $\mathrm{Ce}_{0.1} \operatorname{Pr}_{0.9} \mathrm{O}_{2}$-DC) revealing Pr enrichment on the particles surface. For these estimations the Ce $3 \mathrm{~d}$ and $\mathrm{Pr}$ $3 \mathrm{~d}$ levels were used, whose corresponding binding energies are not very different ( 870 and $970 \mathrm{eV}$, respectively). This corresponds to comparable kinetic energies and thus comparable analysis depth. This degree of praseodymium enrichment on the surface seems to be very dependent on the preparation method used and on the composition considered. As a first inspection on the data, the $\mathrm{Ce} / \mathrm{Pr}$ surface atomic ratio was represented versus the Ce/Pr nominal ratio in Figure 7a, and confronted with the straight line (slope unity). The representation obtained with the co-precipitated samples fits much better to linearity $\left(r^{2}=0.9992\right)$, showing a higher slope than that obtained with the counterpart samples (direct calcination method).

A deeper analysis is obtained by plotting the quotient between these two parameters ( $\mathrm{Ce} / \mathrm{Pr}$ nominal atomic ratio and $\mathrm{Ce} / \mathrm{Pr}$ surface atomic ratio) against $\operatorname{Pr}$ content, as illustrated in Figure 7b. This can be considered as an indication of the Pr enrichment on the particle surface. All the catalysts, with the exception of $\mathrm{Ce}_{0.1} \operatorname{Pr}_{0.9} \mathrm{O}_{2}-\mathrm{DC}$, present a praseodymium-rich surface, but the trend followed by this factor is very different depending on the synthesis route followed. Meanwhile, the enrichment factor is quite constant for the co-precipitation method (1.5 for the low Pr-content catalysts and around 1.4 for the high Pr-content ones). As seen in Figure 7b, the trend of the enrichment factor for the direct calcination method seems to decrease, starting with a very high praseodymium enrichment (for the $\mathrm{Ce}_{0.8} \mathrm{Pr}_{0.2} \mathrm{O}_{2}$-DC and going down towards very low values). The segregation of dopant cations at the surface and domain boundaries of ceria is a well-known phenomenon $[39,48,50]$. The fact of determining higher Pr-enrichment factors for DC-samples compared with CP-samples is consistent with the estimation of 
worse lattice parameter values $a$ measured and, therefore, seems to suggest lower Pr insertion degrees. In general, for nanocrystalline Pr-doped ceria, the segregation of both $\operatorname{Pr}^{3+}$ and $\operatorname{Pr}^{4+}$ cations at the domain boundaries can create pathways for fast chemical diffusion of oxygen [48,51-53], as will be demonstrated below. A brief discussion on the differences that the chemistry governing the synthesis procedures can cause on mixed oxides' particles formation (because different intermediates are generated during the steps of the preparation methods approached) is included in the Supplementary Information as well.

\section{2. $\mathrm{O}_{2}-\mathrm{TPD}$ analysis.}

Even though the reducibility response under several atmospheres $\left(\mathrm{H}_{2}, \mathrm{CO}\right.$, and so on) is a very well-studied issue in the literature for ceria-praseodymia samples, few studies are reported concerning $\mathrm{O}_{2}$-TPD response under inert atmosphere, which can be of relevance in the context of GDI emissions. Figure 8 displays the $\mathrm{O}_{2}$-TPD profiles of all the catalysts investigated. Although $\mathrm{CeO}_{2}$ is a well-known oxygen storage material, $\mathrm{O}_{2}$ desorption under inert atmosphere was barely observed in the case of pure ceria, in agreement with previous results [54] as shown on Figure S3 of the Supplementary Information. The $\mathrm{O}_{2}$ evolved amounts further increased by substituting $\mathrm{Pr}$ in the ceria lattice, consistent with data reported by other authors $[26,55]$, whatever the preparation method considered. This can be attributed to a mixed valence state of $\operatorname{Pr}$, that is, +3 and $+4[54,56]$. Therefore, total $\mathrm{O}_{2}$ amounts evolved from the catalysts increase with the praseodymium content, but not in a gradual way, as will be commented below. Besides, the emission patterns are not exactly the same depending on the preparation method, revealing that Pr content is a paramount feature but the structural characteristics of the 
catalysts are influencing the lability of the lattice oxygen as well. The 3D plots in Figure 8a correspond to the $\mathrm{O}_{2}$ emission profiles in terms of temperature of all the catalysts which belong to the set of oxides prepared by the route of co-precipitation and Figure $8 \mathrm{~b}$ compiles the same representations but concerning the catalysts prepared by the direct calcination of the nitrates mixture. With this 3D format the impact of increasing the $\mathrm{Pr}$ loading can be observed. From a descriptive point of view, a low temperature peak starting from around $300^{\circ} \mathrm{C}$ can be seen whatever the catalyst prepared, but it becomes sharper and higher as the Pr increases from 0.2 to 0.8 (for the samples in Figure 8a) and to 0.7 (for the samples in Figure $8 \mathrm{~b}$ ). The highest values of $\mathrm{O}_{2}$ emission rates in the lowtemperature peak are reached by $\mathrm{Ce}_{0.2} \mathrm{Pr}_{0.8} \mathrm{O}_{2}-\mathrm{CP}$, at $393^{\circ} \mathrm{C}$, revealing an accentuated oxygen lability and, in turn, oxygen mobility, as it will be explained below. After a detailed inspection of the Figures, a medium temperature peak is observed for DCsamples at high Pr contents and, conversely a shoulder of the first peak appears for the CP-samples, eventually becoming a new peak. Finally, the profiles become more and more complicated at very high Pr contents with new peaks appearing above $600-700^{\circ} \mathrm{C}$. The relative maximum values of $\mathrm{O}_{2}$ emission rates both for the low and the hightemperature peaks are achieved by CP-samples.

In order to go deeper into these observations and in an attempt to obtain different correlations, several quantifications and estimations were compiled on Table 3 . The total amounts of the $\mathrm{O}_{2}$ removed in the course of the TPD experiments are presented first, which strongly increase with the Pr loading, starting from $141 \mu \mathrm{mol} \mathrm{O} 2 / \mathrm{g}_{\text {cat }}$ to 913 for the set of samples prepared by co-precipitation and starting from 204 to $1054 \mu \mathrm{mol} \mathrm{O} / \mathrm{g}_{\text {cat }}$, for the samples prepared by direct calcination of nitrates. These amounts are highly interesting keeping in mind that the ideal reduction of $\operatorname{PrO}_{2}$ to $\operatorname{Pr}_{2} \mathrm{O}_{3}$ would correspond to $1445 \mu \mathrm{mol} \mathrm{O}_{2} / \mathrm{g}_{\text {cat }}$ [26], corresponding to the limit $\mathrm{O}_{2}$ amount desorbable. Therefore, in 
order to estimate the degree of the catalysts' reduction after this TPD under inert atmosphere, the percentages of $\mathrm{Ln}^{4+}$ reduced to $\mathrm{Ln}^{3+}$ were estimated on the basis of the whole amount evolved. These amounts are higher for the samples obtained from nitrate calcination ranging from 14.1 to $72.9 \%$ than those estimated from the co-precipitation samples. If the participation of $\operatorname{Pr}$ is considered as the only cation reducible, the corresponding percentages reduced are not the same and depend on the composition and on the method revealing their importance on the samples' reducibility.

Since these experiments induce a progressive reduction of the investigated oxides, they will lead to phases which may be formulated as $\mathrm{Ce}_{1-\mathrm{x}} \operatorname{Pr}_{\mathrm{x}} \mathrm{O}_{(2-\mathrm{y})-\delta}$. The amount of oxygen evolved, and, therefore, the change $(\delta)$ occurred in the stoichiometry of the mixed oxides, could be determined [57]. A limit value of $\delta$ for a bare $\mathrm{CeO}_{2}$ would be 0.5 , which would yield the formation of $\mathrm{Ce}_{2} \mathrm{O}_{3}$, composition achievable at high temperatures and reducing atmospheres $[26,58]$. Conversely, for the theoretical case of a pure $\operatorname{Pr}_{6} \mathrm{O}_{11}$ phase, $\delta$ would present the maximum value of 0.333 . Values compiled on Table 3 indicate high nonstoichiometry levels reached by these samples under these very mild conditions (inert atmosphere). For the pure praseodymias, $\delta$ reaches very similar values to 0.333 , revealing the achievement of the maximum ideal nonstoichiometry, on the understanding that pure $\operatorname{Pr}_{6} \mathrm{O}_{11}$ is the hypothetical initial phase.

On this line and trying to provide insight into the level of oxygen mobility of these samples and the different types of oxygen involved in the emission process, approximate estimations consisting of determining the number of hypothetical ceria layers reduced by means of the extraction of oxygen during the TPD were approached. In order to calculate these values, the maximum amount of reducible oxygen per hypothetical ceria layer was calculated following the procedure and assumptions reported by Wang et al. [59]. Besides, it should be assumed that the estimations are based on the (111) crystal plane 
data of the stoichiometric $\mathrm{O}-\mathrm{Ce}-\mathrm{O}$ tri-layer. Therefore, as the praseodymium content increases in the catalysts, the deviations could become more and more relevant. Assuming these premises, the estimations of hypothetical ceria layers reduced provide evidences of the type of oxygen susceptible to being emitted during this desorption step, and in turn, it provides indirect ideas of the oxygen mobility in the subsurface/bulk of the sample by the possible number of monolayers affected. In this sense, even though the whole amount of $\mathrm{O}_{2}$ extracted is always higher (or slightly higher) for the catalysts prepared with the direct calcination procedure, the number of monolayers affected are lower in most of the compositions studied (with the exception of the extremes of the composition intervals), if compared with the co-precipitation method, providing indirect evidences of an improved oxygen mobility. Lower amounts of $\mathrm{O}_{2}$ extracted from co-precipitated samples during TPD could be tentatively assigned to higher presence of vacancies on most of the fresh samples prepared by co-precipitation (as determined from structural parameters).

Therefore, it can be inferred that: upon praseodymium increase, more monolayers are affected, but not in a gradual way (the effect is more dramatic for the co-precipitated samples); and surface and subsurface oxygen species are involved, even for the catalysts emitting lower amounts of oxygen. The approximate estimations point out an involvement of the bulk oxygen for the Pr-intermediate/rich compositions and in a different extent depending on the preparation method. It is worth paying attention to the finding that the low-temperature peaks cannot be assigned only to surface/subsurface oxygen since, for example, $\mathrm{Ce}_{0.5} \mathrm{Pr}_{0.5} \mathrm{O}_{2}-\mathrm{CP}$ and $\mathrm{Ce}_{0.4} \mathrm{Pr}_{0.6} \mathrm{O}_{2}-\mathrm{CP}$ are able to extract oxygen from 9 and 17 monolayers, respectively. These whole results outline the complexity of these materials and the excellent subsurface/bulk mobility that can be tailored adjusting the Ce/Pr composition and the preparation method. Finally, it is interesting to remark the very high values of $\mathrm{O}_{2}$ emission achieved under inert atmosphere 
if compared with the recent results published concerning Ag-containing perovskites [35] which range from 169 to $326 \mu \mathrm{mol} / \mathrm{g}_{\text {cat }}$, (TPD runs were carried out up to $800^{\circ} \mathrm{C}$ in these mentioned studies).

The following step could be to find out useful correlations to explain the $\mathrm{O}_{2}$ emission trends. In this sense, Figure 9 depicts the whole amounts of $\mathrm{O}_{2}$ emitted along the TPD run in terms of Pr content for the two series of samples. It is clear that, in general terms, the more the Pr content, the more the amount of $\mathrm{O}_{2}$ emitted, (dotted lines); even though the increase is not gradual and two linear trends can be seen (solid lines, if pure praseodymia is not included in both representations) with an inflection point at an intermediate value of ceria-praseodymia compositions. The influence of Pr doping in the improvement of $\mathrm{O}_{2}$ emission for the mixed oxides is much more accentuated at low praseodymium contents (first part of the representations) than at high praseodymium contents (second part of the representation).

A second point of interest could be to find out correlations involving the $\mathrm{O}_{2}$ emitted at low temperature (up to $500^{\circ} \mathrm{C}$ ) which could play a more determinant role in the context of GDI emissions, because the exhaust can reach easily these temperatures (around 500$550^{\circ} \mathrm{C}$ ). The corresponding representations are plotted in Figure 10, for both series. It can be seen that no linear correlations are found and a volcano-curve representation is seen now. The maximum values are obtained at the intermediate compositions (specifically $\mathrm{Ce}_{0.4} \mathrm{Pr}_{0.6} \mathrm{O}_{2}$ ), emphasizing that independently on the BET surface area, the $\mathrm{Ce} / \mathrm{Pr}$ composition plays a crucial role. As a representative example, the $\mathrm{Ce}_{0.2} \mathrm{Pr}_{0.8} \mathrm{O}_{2}$-CP catalyst with $10 \mathrm{~m}^{2} / \mathrm{g}$ of surface area yields higher $\mathrm{O}_{2}$ emission than its counterpart prepared by direct calcination $\left(31 \mathrm{~m}^{2} / \mathrm{g}\right)$, thus allowing us to assert that the external areas seem not to play a crucial role. On the other hand, if the corresponding $\mathrm{Ce} / \mathrm{Pr}$ surface atomic ratios, extracted from XPS analysis, are included on the representation (values in 
parentheses), it can be seen that for every couple of catalysts with the same composition, the one which exhibits higher Pr-enrichment is situated always higher on the trend, providing evidences of the relevant influence of this parameter on the capacity of making the $\mathrm{O}_{2}$ evolving at low-medium temperatures more labile [53,60]. Previous reports by Andana et al. $[61,62]$ also indicated $\mathrm{Ce} / \mathrm{Pr}$ ratios at the intermediate composition, $(0.5 / 0.5)$, as the most effective one, thanks to its high oxygen mobility and its high reducibility.

\subsection{Catalytic performances of soot combustion under inert atmosphere.}

The efficiency of the own active oxygen species released from the catalysts to oxidise soot under these demanding conditions (inert atmosphere; loose contact) was firstly evaluated in the same TG-MS apparatus. As far as these authors are concerned, these types of experiments have been reported in the literature only under the tight contact mode $[35,54,63,64]$. The soot combustion experiments under inert atmosphere would mimic the most demanding conditions found in the exhaust of GDI engines (under normal stoichiometric engine operation, no $\mathrm{O}_{2}$ in the stream).

Since the catalysts present a wide range of $\mathrm{O}_{2}$ evolution patterns, presented in Figure 9, the plots of emission rates versus temperature (Figures $11 \mathrm{a}-\mathrm{h}$ ) include both the raw $\mathrm{O}_{2}$ emission from the catalysts (blue dotted line, obtained under TPD- $\mathrm{O}_{2}$ ) and the corresponding gas profiles monitored during the experiment of soot combustion (solid lines: $\mathrm{O}_{2}$ level, $\mathrm{CO}_{2}$ and $\mathrm{CO}$ emission, -if any-). By plotting this type of "combined" representations many aspects can be revealed: i) how reactive these $\mathrm{O}_{2}$ species (freshly emitted) are towards soot as a function of temperature; ii) if the utilization of the $\mathrm{O}_{2}$ emitted from the catalysts is coupled to the soot combustion reaction (either delayed or 
moved forward); iii) if there is a closed balance between the $\mathrm{O}_{2}$ consumed and the $\mathrm{CO}_{2} / \mathrm{CO}$ emission due to the soot combustion process. Since the whole catalysts emit $\mathrm{CO}_{2}$ under inert atmosphere (due to decarbonation processes suffered during heating) [24], the corrections carried out to obtain the representations commented above are detailed in the Supplementary Information.

Figure $11(\mathrm{a}-\mathrm{h})$ depict the corresponding catalytic profiles for the set of catalysts prepared by direct calcination, (with the exception of $\mathrm{Ce}_{0.8} \operatorname{Pr}_{0.2} \mathrm{O}_{2}$, which emits a low $\mathrm{O}_{2}$ amount), meanwhile Figure S4 (a-h) illustrates the profiles of the same compositions, prepared from the co-precipitation route (for comparative purposes). Supplementary Information also compiles the curves obtained from the uncatalyzed reaction under 1000ppm $\mathrm{O}_{2} / \mathrm{He}$ (Figure S5).

Compared with the conversion profiles of the uncatalyzed reaction, all the catalysts are active to oxidise soot at lower temperatures than a gas stream containing $1000 \mathrm{ppm}$ $\mathrm{O}_{2} / \mathrm{He}$, evidencing that the own lattice oxygen can initiate and continue the soot combustion efficiently from a quite interesting temperature (around $300^{\circ} \mathrm{C}$ ), without $\mathrm{O}_{2}$ in the gas stream, even under poor contact of soot and catalyst. As far as the authors are concerned, this experimental evidence had been demonstrated by other authors only under tight contact conditions [35, 54, 63, 64].

As derived from Figure $\mathrm{S} 5, \mathrm{CO}_{2}$ emission caused by the uncatalyzed soot combustion starts to be relevant at around $450^{\circ} \mathrm{C}$, being the onset temperature of $\mathrm{CO}$ a little bit lower than $600^{\circ} \mathrm{C}$. The selectivity to $\mathrm{CO}_{2}$ formation with regard to the total emitted products $\left(\mathrm{CO}_{\mathrm{x}}\right)$ is $78 \%$. These experimental data contrast with the patterns in Figures 11 and S4, suggesting the occurrence of the catalytic path for the ceria-praseodymia catalysts investigated. 
The soot conversion profiles of all the catalysts tested under loose contact provide evidences of the good catalytic responses of all the catalysts investigated with certain differences on their performances, depending on their different profiles of $\mathrm{O}_{2}$ emission (in turn dependent, mainly, on Ce/Pr composition). Quantitative data estimated from the catalytic profiles are illustrated on Table 4 and support and strengthen the discussion of the catalytic behaviour and the deduction of the mechanistic implications. It has been demonstrated that the low-temperature peak, ranging roughly from 300 to $500^{\circ} \mathrm{C}$, is partially used for the soot combustion process, depending on its intensity and on the formulation of the catalyst, with concomitant $\mathrm{CO}_{2}$ emission. Other potential factor to pay attention to is the possible influence of the varied catalyst morphologies and pore size distribution (more or less presence of large mesopores as a relevant feature) in terms of "true" oxygen delivery efficiency. A tentative correlation is presented below when analysing the soot combustion activity in the relevant temperature range of the desired application (up to $500^{\circ} \mathrm{C}$ ).

From $500^{\circ} \mathrm{C}$ on, whether a low continuous level of $\mathrm{O}_{2}$ or several peaks are presented in the pattern of the $\mathrm{O}_{2}$-TPD or not, no $\mathrm{O}_{2}$ at all is detected during the soot combustion process. In other words, it is effectively consumed for soot oxidation. The $\mathrm{O}_{2}$ consumption during these tests approximately matches with the $\mathrm{CO}_{2}$ emitted amounts in most of the samples (with deviations lower than $10 \%$ ). However $\mathrm{Ce}_{0.2} \mathrm{Pr}_{0.8} \mathrm{O}_{2}-\mathrm{CP}$ presents an imbalance of $25 \%$, revealing that the $\mathrm{O}_{2}$ consumption estimated from the subtraction among the $\mathrm{O}_{2}$ desorption from TPD (under inert atmosphere) and the $\mathrm{O}_{2}$ level during the soot combustion (see corresponding quantification amounts on Table 4) is insufficient to yield the $\mu$ mol of $\mathrm{CO}_{2}$ estimated.

Additionally, after a detailed inspection of the catalytic profiles, it can be reported another experimental evidence: the $\mathrm{CO}_{2}$ emission profiles at medium-high temperatures 
(observe as representative example the Figure 11a) indicate a shift towards lower temperatures of the combustion curve $\left(\mathrm{CO}_{2}\right.$ level) compared with the own $\mathrm{O}_{2}$ emission level of the catalyst (lattice oxygen, represented by dotted line). The results seem to evidence that the presence of soot, even under loose contact mode, is acting as a driving force [65], "extracting" lattice oxygen at higher rates, and, in some cases, in higher amounts than the inert atmosphere by itself. Promptly, the surface/subsurface lattice oxygen is being replaced by inner oxygen in agreement with the good bulk oxygen mobility that seem to exhibit these samples [63], whose low-temperature peaks during $\mathrm{O}_{2}$-TPD experiments reflect the reduction of subsurface/bulk layers; as tentatively estimated by the calculations showed above. The presence of soot helps the lattice oxygen to become more labile [64], since the samples are characterized by stabilizing a large number of vacancies (see estimations of $\delta$ parameter).

In this sense, and with the purpose of exploring the influence of the quality and number of the contact points between catalyst and soot on the catalytic performance, experiments under tight contact mode were conducted for selected catalysts as well (Figures 12a-f).

The complementary soot combustion tests under tight contact mode are presented now with the aim of shedding some light on this issue. As expected, the activity towards soot combustion under this mixture mode is highly promoted compared with the loose contact mode, thus indicating the importance of the number and quality of contact points created by an intimate mixing in a mortar [66]. In addition to this, there is no hardly " $\mathrm{O}_{2}$ slip" during the soot combustion reaction, suggesting, a priori, the usage of all the oxygen susceptible to release. The onset temperatures of soot combustion are clearly brought forward and the $\mathrm{CO}_{2}$ profiles are becoming sharper, with very high maximum $\mathrm{CO}_{2}$ emission rates, if compared with those values obtained under loose contact mode. It is 
worth indicating that the six catalysts selected to be shown in Figure 12 under this type of contact (including different compositions and both preparation procedures) exhibit imbalance among the $\mathrm{O}_{2}$ consumed and the $\mathrm{CO}_{2} / \mathrm{CO}$ emitted. Even considering the whole amount of $\mathrm{O}_{2}$ subject to emit during the $\mathrm{O}_{2}-\mathrm{TPD}$, these amounts are insufficient to oxidise soot at the percentage of conversions measured. Finally, $\mathrm{CO}$ is detected as a minor reaction product (at high temperatures) for all the catalysts investigated. All these experimental evidences reflect the good delivery/transfer properties of lattice oxygen from these catalysts to the soot surface due to the excellent mobility of the oxide in the lattice, interestingly improved by the intimate contact of soot and catalyst. Thus, the active oxygen species, precursors of the $\mathrm{O}_{2}$ emitted during a TPD under inert atmosphere and additional lattice oxygen of the mixed oxides are "extracted" during the soot combustion process and effectively transferred to the soot surface yielding $\mathrm{CO}_{2}$ and minor amounts of $\mathrm{CO}$ at the highest temperatures. The abilities of the ceria-praseodymia/soot mixtures under tight contact and inert atmosphere to reach high soot combustion percentages had not been reported in the literature yet. However, some authors, such as Machida et al. [64] have published the relevance of a possible reaction pathway consisting of the reaction between soot and active lattice oxygens at the soot/ceria interface.

In order to keep in mind a clear picture of the effect of the composition and the preparation method on the soot combustion activity under the experimental conditions studied (loose and tight contact), Figure 13 is an attempt to illustrate that influence in a simple way, combining all the variables. The soot combustion percentage is plotted in a 3D bar chart versus $\mathrm{Pr} /(\mathrm{Ce}+\mathrm{Pr})$ ratio, method of preparation approached and type of soot/catalyst contact. Experiments conducted under loose contact mode do not reflect gradual trends with the Pr content, and in general lower levels of soot combustion are seen for low praseodymium content catalysts and higher for high praseodymium content 
catalysts. This is linked to the idea that the lattice oxygen likely to be emitted at low temperatures is not employed efficiently, (only partially, depending on several factors). Conversely, clearer tendencies can be noted under tight contact mode, mainly for the direct calcination method, where the higher the praseodymium loading, the higher the soot combustion percentage achieved. The results revealed an efficient use/transfer of the lattice oxygen under this mode of operation, in line with the results published by Machida et al., who suggested the high reactivity of lattice oxygens in pre-reduced ceria [64], even though these authors did not contribute with specific experimental evidences.

Finally, in an attempt to discuss quantitative data obtained from the catalytic tests, but integrated up to $500^{\circ} \mathrm{C}$, (much more useful for the desired GDi application, where the exhaust gas can easily reach $500-550^{\circ} \mathrm{C}$ ), complementary estimations were compiled on Table 4 (values on parentheses). Under tight contact conditions, Pr loading continues to be a relevant parameter to determine the soot combustion rate up to $500^{\circ} \mathrm{C}$, within every series. However, now, considering this interval of temperature, the most interesting sample is not $\mathrm{PrO}_{2}-\mathrm{DC}$, but that obtained from $\mathrm{CP}$ series $\left(\mathrm{Ce}_{0.1} \mathrm{Pr}_{0.9} \mathrm{O}_{2}\right.$, since only selected catalysts were tested under this mode of contact). Interestingly, even though the lowest temperature interval is considered, the soot combustion activity is still very satisfactory if compared with that measured from the whole interval of temperatures (up to $950^{\circ} \mathrm{C}$ ), which reveals the interest of this type of materials for the mentioned application.

Much more complex is the interpretation of the soot combustion results measured up to $500^{\circ} \mathrm{C}$ under loose contact mode and the possible correlations that could be reported. Even though the activity remains relevant despite of the unfavourable reaction conditions tested (low temperature range, poor degree of contact, no $\mathrm{O}_{2}$ in the gas stream....) and all the catalysts are significantly active for the process, to a greater or lesser extent, there is not a clear trend in activity as that seen for tight contact conditions with the Pr content. 
On the other hand, the samples do not follow either the tendency in "volcano curve" shown by the representation of the amount of $\mathrm{O}_{2}$ emitted up to $500^{\circ} \mathrm{C}$ (illustrated on Fig. 10), thus suggesting that other factors can play a role under these reactions conditions. In line with the findings reported by Liu and co-workers [41, 42], and taking into consideration the poor contact conditions achieved in the loose contact mode, the possible influence of the presence and distribution of large mesopores, that could be critical under the starting situation of the low dispersion of soot particles onto the catalyts' surfaces, (see Fig. S2) is tentatively proposed as one feature to take into account. Interestingly, and selecting the subset of catalysts with composition $\mathrm{Ce}_{0.7} \operatorname{Pr}_{0.3} \mathrm{O}_{2}, \mathrm{Ce}_{0.6} \operatorname{Pr}_{0.4} \mathrm{O}_{2}, \mathrm{Ce}_{0.5} \operatorname{Pr}_{0.5} \mathrm{O}_{2}$ and $\mathrm{Ce}_{0.4} \operatorname{Pr}_{0.6} \mathrm{O}_{2}$, a clear trend is followed concerning lower soot combustion activities up to $500^{\circ} \mathrm{C}$, for both series (lower amounts of $\mathrm{CO}_{2} / \mathrm{g}_{\text {cat }}$ quantified in parentheses, see Table 4), in connection with a decreasing contribution of large mesopores, especially evident for the DC-subset. It can be noted, as well, a larger contribution of mesopores for the DC series (with regard to CP-series), and accordingly, higher reactivities than those quantified for CP-series (see Figures $4 \mathrm{a}$ and $4 \mathrm{~b}$ ). This seems to be valid even comparing the couple of catalysts that release the same amount of $\mathrm{O}_{2}$ up to $500^{\circ} \mathrm{C}$ during TPD $\left(\mathrm{Ce}_{0.6} \operatorname{Pr}_{0.4} \mathrm{O}_{2}-\mathrm{DC}\right.$ and $\left.\mathrm{Ce}_{0.6} \operatorname{Pr}_{0.4} \mathrm{O}_{2}-\mathrm{CP}\right)$.

As a summary, the whole results presented ranging such a high number of samples, along with the two modes of contact tested, allow us to deduce some mechanistic implications in the context of the soot combustion by lattice oxygen for these ceriapraseodymia mixed oxides that will be discussed in the next section.

3.4. Discussion about the mechanisms taking place during soot combustion under inert atmosphere. 
It is generally assumed that the soot oxidation reaction proceeds through a Mars-Van Krevelen mechanism, where the lattice oxygen in the first few surface layers of ceria is transferred onto the soot, and gaseous $\mathrm{O}_{2}$ fills up the vacancies created on the oxide in a subsequent step $[63,66]$. The mechanism of action is also associated with the availability of adsorbed active oxygen species that spillover onto the soot surface. However, the situation can be rather different when performing the soot oxidation under inert atmosphere [63]. The understanding of the mechanisms involved may be relevant from a practical and fundamental point of view, taking into account that in GDI applications and due to the high efficiency of the upstream or integrated TWC, there is no appreciable oxygen available as oxidant in normal stoichiometric $(\lambda=1)$ operation, and it is available only during short and low frequent fuel cuts (especially in highway driving mode) [18]. It is obvious that when surface lattice oxygen of ceria-based catalysts is used for soot oxidation, the resultant vacant sites will be refilled by sub-surface/bulk oxygen and the dynamics of the processes will be governed by the oxygen storage capacity (OSC) of the catalysts [63]. Nevertheless, the extent at which this can take place and a plausible proposal of the key elemental steps is far from being perfectly stablished. At the sight of the overall results here presented, where the sets of catalysts prepared exhibit complex and very different patterns of $\mathrm{O}_{2}$ delivery under inert atmosphere, the comparison among the $\mathrm{O}_{2}$ profiles during TPD under inert atmosphere and the soot combustion profiles under loose contact or tight contact mode, allows us to propose the following key steps, differentiating both contact modes and intervals of temperatures:

i) Loose contact at low temperatures (from room temperature up to $500^{\circ} \mathrm{C}$ ). As anticipated above, the supply of $\mathrm{O}_{2}$ from the catalyst seems not to be the rate-limiting step, since $\mathrm{O}_{2}$ always emerged during the soot combustion reaction in this interval of temperatures, whatever the formulation of the 
catalysts (compare blue dotted and solid lines in Figures 11 and S4). The difference in $\mathrm{O}_{2}$ levels is attributed to differences in the extent of utilization in soot combustion and consequently $\mathrm{CO}_{2}$, as the only combustion product evolves simultaneously. Therefore, the reaction must proceed in such a way:

$$
\mathrm{C}+\mathrm{O}_{2}{ }^{*} \rightarrow \mathrm{CO}_{2}(\mathrm{R} .1)
$$

These $\mathrm{O}_{2}{ }^{*}$ species, freshly emitted from the catalyst, could be characterized for a superior reactivity, since the uncatalyzed reaction conducted with $1000 \mathrm{ppm} \mathrm{O}_{2} / \mathrm{N}_{2}$ oxidises the soot very slightly and differently from the profiles seen (Figure 11). As claimed by several authors $[41,42,67]$, the very reactive surface oxygen species, $\mathrm{O}_{\mathrm{x}}{ }^{-}$, are continuously consumed by soot and regenerated via catalyst bulk oxygen (if there is no $\mathrm{O}_{2}$ in the gas phase). Consequently, $\mathrm{O}_{2}{ }^{*}$ species is presumed to proceed from $\mathrm{O}_{\mathrm{x}}{ }^{-}$species (and/or successive transformations into highly reactive $\left.\mathrm{O}_{2}^{-}\right)[41,42,67]$.

By a detailed analysis of the profiles, it is considered that the rate between active oxygen species and soot is lower than the reaction in which active oxygen species recombine/transform forming molecular dioxygen $\left(\mathrm{O}_{2}{ }^{*}\right.$ under these experimental conditions). These freshly-created $\mathrm{O}_{2}$ species attack the soot surface. Under loose contact conditions (interval of low temperatures), it can be assumed that only a fraction of the active oxygen generated by the catalyst is useful for soot oxidation. The loose contact between catalyst and soot particles makes the "active oxygen" transfer to soot difficult, well evidenced by FESEM analysis (see Figs. S2 on the Supplementary Information) and the active species will be transformed/recombined to yield $\mathrm{O}_{2}{ }^{*}$ before they react with soot via gaseous migration [68].

Under the conditions tested and supported by the quantifications estimated, a large contribution of mesopores presence in the catalyst could favour a "true" oxygen delivery efficiency and, consequently, a higher soot oxidation performance. 
ii) Loose contact at high temperatures (from $500^{\circ} \mathrm{C}$ up to $950^{\circ} \mathrm{C}$ ).

Generally, from $500^{\circ} \mathrm{C}$ on, $\mathrm{O}_{2}$ does not evolve during the soot combustion tests whatever the catalyst considered. Besides, the detailed inspection of the profiles suggests that the $\mathrm{CO}_{2}$ emission, as a consequence of soot combustion, is not concomitant with the $\mathrm{O}_{2}$ profile given by the TPD-O 2 tests, but it seems to be quite shifted towards lower temperatures. This suggests that the soot is acting as a "driving force" and is being oxidised directly by the $\mathrm{O}$ active species (O-cat in the reaction steps), directly transferred or spilled towards the soot surface. As claimed by several authors $[41,42,67]$, these species presumably consist of highly reactive $\mathrm{O}_{\mathrm{x}}{ }^{-}$species, as commented above. The formed surface vacancies are replenished by sub-surface/bulk oxygen. Contrarily to what is inferred at low temperatures, now the direct reaction between active oxygen species and soot is much faster than the reaction in which active oxygen species transform/decompose forming molecular oxygen, as stated by several authors studying mainly soot combustion under tight conditions $[68,69]$. Therefore, the proposed key steps would be:

$$
\begin{gathered}
\mathrm{C}+\mathrm{O}-\text { cat } \rightarrow \mathrm{CO}(\mathrm{R} .2) \\
\mathrm{CO}+\mathrm{O} \text {-cat } \rightarrow \mathrm{CO}_{2}(\mathrm{R} .3)
\end{gathered}
$$

as reported by Andana et al. [61] or alternatively:

$$
\mathrm{C}+2 \mathrm{O}-\text { cat } \rightarrow \mathrm{CO}_{2}(\mathrm{R} .4)
$$

could be operating as well.

This can be clearly evidenced because ceria-praseodymia samples (compared with other ceria-based catalysts) present a relevant ability to stabilise a large number of vacancies on their structures, and eventually, enough 
subsurface/bulk oxygen species can migrate to the surface according to the good $\mathrm{O}_{2}$-TPD profiles.

iii) Tight contact.

Whatever the catalyst selected, there is hardly $\mathrm{O}_{2}$ emission (only very small amounts at very low temperatures, compared with the loose contact mode). $\mathrm{CO}_{2}$ emission is dramatically shifted towards lower temperatures (consider the $\mathrm{Ce}_{0.2} \mathrm{Pr}_{0.8} \mathrm{O}_{2}-\mathrm{CP}$ sample, in Figure 12-c, as a representative example), with values of $\mathrm{T}_{\text {ignition (tight contact) }}$ of $200^{\circ} \mathrm{C}$, compared with the onset temperature of $\mathrm{CO}_{2}$ emission under loose contact mode $\left(\mathrm{T}_{\text {ignition }(\text { loose } \text { contact })}=300^{\circ} \mathrm{C}\right)$. Besides, there is a notorious imbalance among the $\mathrm{O}_{2}$ released under inert atmosphere and the needed one to oxidise soot at the extent observed under tight contact conditions $\left(788 \mu \mathrm{mol} \mathrm{O} / \mathrm{g}_{\text {cat }}\right.$, -see Table 4-, versus $966 \mu \mathrm{mol} \mathrm{CO} / \mathrm{g}_{\text {cat }}+299$ $\left.\mu \mathrm{mol} \mathrm{CO} / \mathrm{g}_{\text {cat }}\right)$ providing evidences that more $\mathrm{O}_{2}$ than that evolving from $\mathrm{O}_{2-}$ TPD under inert atmosphere is involved in the soot combustion process. In addition, the maximum soot combustion rates under tight contact conditions are higher than those achieved under loose contact conditions), supporting the idea that under the most favourable tight contact conditions a large population of O-cat from the oxides can migrate to the soot surface (both by spillover mechanisms or surface diffusion mechanisms), as explained by other authors $[41,67,69]$.

Differently from loose contact mode, under tight contact mode, minor amounts of $\mathrm{CO}$ always emerge at high temperatures, consistently with the reaction scheme (R.2). 
Finally, the benefit of having obtained a set of catalysts with such a high activity (very good oxygen mobility, very active as oxygen "deliverers" under inert atmosphere...) has allowed us to confirm some of the mechanisms proposed in the literature in the last years $[60,63]$. Soler et al. [66] in his very elegant work dealing with the proposal of the mechanisms of carbon soot oxidation in ceria-based catalysts, provided a study of surface/subsurface of the catalysts under catalytic conditions by photoelectron spectroscopy, further validating his own mechanism working under super-tight conditions. In the present work, the catalytic curves obtained in the whole range of temperature, under loose and tight conditions, provided new insights, not only into the factors governing a high mobility of lattice oxygen in the ceria-based catalysts but also in an effective lattice oxygen transfer to the soot surface under determined work conditions, revealing the differences in the distinct ranges of temperatures analyzed.

\section{Conclusions}

Two series of ceria-praseodymia mixed oxides with varying compositions have been prepared by using two simple methods of synthesis. Their structural and textural properties have been systematically investigated and seem to be dependent on the methods of preparation and the Pr content.

The mixed oxides prepared can create large populations of oxygen vacancies on their structures according to their high values of nonstoichiometry estimated from TPDs under inert atmosphere. The praseodymium incorporation onto the ceria enhances the oxygen mobility in the subsurface/bulk of the sample favoring higher $\mathrm{O}_{2}$ released amounts under inert atmosphere. The intermediate compositions can promote more accentuated $\mathrm{O}_{2}$ emissions at moderate temperatures (up to $500^{\circ} \mathrm{C}$ ). These mixed oxides are characterized 
by surface Pr-enrichment which plays a relevant role in their capacity of becoming lattice oxygen more labile.

The efficiency of the own active oxygen species released from the catalyst to oxidize soot under inert atmosphere, even under loose contact mode, has been well demonstrated. As far as the authors are concerned this experimental fact had been previously reported, only under tight contact conditions, for ceria-based catalysts.

Under tight contact conditions, Pr loading seems to be one of the most relevant factors to determine soot combustion rates. The correlations are much more difficult to build under loose contact conditions, even though the best catalysts are those with high Pr-content in every series. Tentatively, the presence of mesopores is considered as a factor to take into consideration here for selected subset of samples.

The pathways of the mechanism taking place seem to be dependent on the temperature and mainly on the type of contact among soot and catalyst. Under loose contact conditions and low-medium temperature, the $\mathrm{O}_{2}$ freshly emitted from the catalyst can oxidize soot more efficiently than a diluted $\mathrm{O}_{2}$-gas stream. Conversely, under more severe conditions (higher temperature or tight contact conditions), the soot acts as a "driving force" and the own lattice oxygen species can be transferred directly towards soot surface in an efficient way. The results of this work are in agreement with the possible reactions pathways proposed by other authors in the last years.

The experimental evidences here reported can be applied for the rationale design of effective catalyst in the framework of catalyzed Gasoline Particle Filters, where soot needs to be oxidized under no appreciable oxygen, because it is only available during fuel cuts. 


\section{Acknowledgements}

The authors gratefully acknowledge the financial support of Generalitat Valenciana (PROMETEO/2018/076), MINECO (CTQ2015-64801-R) and the UE (FEDER funding). Also, JCMM acknowledges Spanish Ministry of Education, Culture and Sports for the financial support through a FPU grant (FPU17/00603).

\section{References}

1. Regulation (EU) No 333/2014 of the European Parliament and of the Council of 11 March 2014 amending Regulation (EC) $\mathrm{N}^{0} 443 / 2009$ to define the modalities for reaching the 2020 target to reduce $\mathrm{CO}_{2}$ emissions from new passenger cars.

2. S. Pischinger, Top. Catal. 59 (2016) 834-844.

3. F. Zhao, M.C. Lai, D.L. Harrington, Prog. Energy Combust. Sci. 25 (1999) 437-562.

4. Y. Ito, T. Shimoda, T. Aoki, Y. Shibagaki, K. Yuuki, H. Sakamoto, C. Vogt, T. Matsumoto, W. Heuss, P. Kattouah, M. Makino, K. Kato, Advanced CeramicWall Flow Filter for Reduction of Particulate Number Emission of Direct Injection Gasoline Engines. SAE Technical Paper 2013-01-0836, 2013.

5. T.W. Chan, E. Meloche, J. Kubsh, D. Rosenblatt, R. Brezny, G. Rideout, Evaluation of a Gasoline Particulate Filter to Reduce Particle Emissions from a Gasoline Direct Injection Vehicle. SAE Technical Paper 2012-01-1727, 2012.

6. W. Piock, G. Hoffmann, A. Berndorfer, P. Salemi, B. Fusshoeller, Strategies towards Meeting Future Particulate Matter Emission Requirements in Homogeneous Gasoline Direct Injection Engines. SAE Technical Paper 201101-1212, 2011.

7. T. Shimoda, Y. Ito, C. Saito, T. Nakatani, Y. Shibagaki, K. Yuuki, H. Sakamoto, C. Vogt, T. Matsumoto, Y. Furuta, W. Heuss, P. Kattouah, M. Makino, Potential of a Low Pressure Drop Filter Concept for Direct Injection Gasoline Engines to Reduce Particulate Number Emission. SAE Technical Paper 2012-01-1241, 2012.

8. P. Whitaker, P. Kapus, M. Ogris, P. Hollerer, Measures to Reduce Particulate Emissions from Gasoline DI Engines. SAE Technical Paper 2011-01-1219F, 2011.

9. S.. Philipp, R. Hoyer, F. Adam, S. Eckhoff, R. Wunsch, C. Schoen, G. Vent, Exhaust Gas Aftertreatment for Lean Gasoline Direct Injection Enginespotential for Future Applications. SAE Technical Paper 2013-01-1299, 2013.

10. T.V. Johnson, Review of Emerging Trends on Gasoline Emissions Control, $3^{\text {rd }}$ International Conference Advanced Emission Control Concepts for Gasoline Engines, May 2014, Düsseldorf, (Germany). 
11. P. Nicolin, D. Rose, F. Kunath, T. Boger, Modeling of the Soot Oxidation in Gasoline Particulate Filters. SAE Technical Paper 2015-01-1048, 2015.

12. A. Mamakos, N. Steininger, G. Martini, P. Dilara, Y. Drossinos, Atmos. Environ. 77 (2013) 16-23.

13. A. Mamakos, G. Martini, A. Marotta, U. Manfred, J. Aerosol Sci. 63 (2013) 115-125.

14. International Agency for Research on Cancer: Outdoor Air Pollution a Leading Environmental Cause of Cancer Deaths, 2013. Press Release N²21.

15. S. Spiess, K.-F. Wong, J.-M. Richter, R. Klingmann, Top. Catal. 56 (2013) 434-439.

16. A. Mamakos, et al. Feasibility of Introducing Particulate Filters on Gasoline Direct Injection Vehicles, JRC Scientific and Policy Report, JRC68675, EUR 25297 EN EU Commission, 2011.

17. S. Choi, H. Seong, Comb. Flame 162 (2015) 2371-2389.

18. T. Boger, D. Rose, P. Nicolin, N. Gunasekaran, T. Glasson, Emiss. Control. Sci. Technol. 1 (2015) 49-63.

19. S. Liu, X. Wu, D. Weng, R. Ran, J. Rare Earths 33 (2015) 567-590.

20. I. Atribak, F. E. López-Suárez, A. Bueno-López, A. García-García, Catal. Today 176 (2011) 404-408.

21. N. Guillén-Hurtado, A. Bueno-López, A. García-García, Appl. Catal. A 437438 (2012) 166-172.

22. J. Giménez-Mañogil, A. García-García, Fuel. Process. Tech. 129 (2015) 227235.

23. N. Guillén-Hurtado, A. García-García, A. Bueno-López, Appl. Catal. B 174175 (2015) 60-66.

24. J. Giménez-Mañogil, N. Guillén-Hurtado, S. Fernández-García, X. Chen, J.J. Calvino-Gámez, A. García-García, Top. Catal. 59 (2016) 1065-1070.

25. B. de Rivas, N. Guillén-Hurtado, R. López-Fonseca, F. Coloma-Pascual, A. García-García, J.I. Gutiérrez-Ortiz, A. Bueno-López, Appl. Catal. B 121-122 (2012) 162-170.

26. A.D. Logan, M. Shelef, J. Mater. Res. 9 (1994) 468-475.

27. L. Ilieva L, G. Pantaleo, I. Ivanov, R. Zanellac, J.W. Sobczak, W. Lisowski, A.M. Venezia, D. Andreeva, Catal. Today 175 (2011) 411-419.

28. E. Moretti, L. Storaro, A. Talon, M. Lenarda, P. Riello, R. Frattini, M.d.V. Martínez de Yuso, A. Jiménez-López, E. Rodríguez-Castellón, F. Ternero, A. Caballero, J.P. Holgado, Appl. Catal. B 102 (2011) 627-637.

29. A. Laachir, V. Perrichon, A. Badri, J. Lamotte, E. Catherine, J.C. Lavalley, J. El Fallah, L. Hilaire, F. Le Normand, E. Quéméré, G.N. Sauvion, O. Touret, J. Chem. Soc. Faraday Trans. 87 (1991) 1601-1609.

30. H. Borchet, Y.V. Frolova, V.V. Kaichev, I.P. Prosvirin, G.M. Alikina, A.I. Lukashevich, V.I. Zaikovskii, E.M. Moroz, S.N. Trukhan, V.P Ivanov, E.A. Paukshtis, V.I. Bukhtiyarov, V.A. Sadykov, J. Phys. Chem. B 109 (2005) 5728-5738.

31. J. Giménez-Mañogil, A. García-García, Appl. Catal. A 542 (2017) 226-239.

32. Y. Kameya, K.O. Lee, J. Nanopart. Res. 15 (2013) 2006. 
33. Y. Gao, A. Duan, S. Liu, X. Wu, W. Liu, M. Li, S. Chen, X. Wang, D. Weng, Appl. Catal. B 203 (2017) 116-126.

34. J.P.A. Neeft, M. Makkee, J.A. Moulijn, Chem. Eng. J. 64 (1996) 295-302.

35. W.Y. Hernández, D. López-González, S. Ntais, C. Zhao, A. Boréave, P. Vernoux, Appl. Catal. B 226 (2018) 202-212.

36. GQ. Xie, MF. Luo, M. He, P. Fang, JM. Ma, YF. Ying, ZL. Yang, J. Nanopart. Res. 9 (2007) 471-478.

37. M. Rajendran, K.K. Mallick, A.K. Bhattacharya, J. Mater. Sci. 33 (1998) 50015006.

38. A.R. West, Solid State Chemistry and its Applications, Ed. John Wiley and Sons (1995).

39. B.M. Reddy, G. Thrimurthulu, L. Katta, Y. Yamada, S.E. Park, J. Phys. Chem. C 113 (2009) 15882-15890.

40. M.Y. Sinev, G.W. Graham, L.P. Haack, M. Shelef, J. Mate. Res. 11 (1996) 1960-1971.

41. S. Liu, X. Wu, W. Liu, W. Chen, R. Ran, M. Lin, D. Weng, J. Catal. 337 (2016) 188-198.

42. H. Wang, S. Liu, Z. Zhao, X. Zou, M. Liu, W. Liu, X. Wu, D. Weng, Catal. Sci.Technol. 7 (2017) 2129-2139.

43. J.R. McBride, K.C. Hass, B.D. Poindexter, W.H. Weber, J. Appl. Phys. 76 (1994) 2435-2441.

44. V.G. Keramidas, W.B. White, J. Chem. Phys. 59 (1973) 1561-1562.

45. K. Krishna, A. Bueno-López, M. Makkee, J.A. Moulijn, Appl. Catal. B 75 (2007) 189-200.

46. S. Somacescu, V. Parvulescu, J.M. Calderon-Moreno, S.-H. Suh, P. Osiceanu, B.-L. Su, J. Nanopart. Res. 14 (2012) 1-17.

47. M.F. Luo, Z.L. Yan, L.Y. Jin, J. Mol. Catal. A: Chem. 260 (2006) 157-162

48. M.F. Luo, Z.L. Yan, L.Y. Jin, M. He, J. Phys. Chem. B 110 (2006) 1306813071.

49. M. Guo, J. Lu, Y. Wu. Y. Wang. M.F. Luo, Langmuir 27 (2011) 3872-3877.

50. Y. Ito, Y. Lei, N.D. Browning, T.J. Mazanec, Mater. Res. Soc. Symp. Proc. 703 (2002) 489-494.

51. P. Knauth, H.L. Tuller, Mater. Res. Soc. Symp. Proc. 548 (1999) 429-442.

52. K.M. Ryan, J.P. McGrath, R.A. Farrell, W.M. O’Neill, C.J. Barnes, M.A. Morris, J. Phys. Condens. Matter 15 (2003) L49-L58.

53. V.A. Sadykov, Y.V. Frolova, G.M. Alikina, A.I. Lukashevich, V.S. Muzykantov, V.A. Rogov. E.M. Moroz, D.A. Zyuzin, V.P. Ivanov, H. Borchet, E.A. Paukshtis, V.I. Bukhtiyarov, V.V. Kaichev, S. Neophytides, E. Kemnitz, K. Scheurell, React. Kinet. Catal. Lett. 86 (2005) 21-28.

54. K. Harada, T. Oishi, S. Hamamoto, T. Ishihara, J. Phys. Chem. C 118 (2014) 559-568.

55. J.T.Mullhaupt, U.S. Patent 3980763 (1976).

56. K. Harada, T. Oishi, S. Hamamoto, T. Ishihara, Bull. Chem. Soc. Jpn. 86 (2013) 963-967. 
57. S. Bernal, G. Blanco, J.M. Pintado, J.M. Rodríguez-Izquierdo, M.P. Yeste, Catal. Comm. 6 (2005) 582-585.

58. A. Trovarelli in Catalysis by Ceria and Related Materials Catalytic Science Series. Vol. 2. Imperial College Press, London (2002).

59. Y. Wang, J.P. de Boer, F. Kapteijn, M. Makkee, ChemCatChem. 8 (2016) 102105.

60. K.I. Hadjiivanov, T.N. Vasyllov, Adv. Catal. 47 (2002) 307-511.

61. T. Andana, M. Piumetti, S. Bensaid, N. Russo, D. Fino, R. Pirone, Appl. Catal. B 197 (2016) 125-137.

62. T. Andana, M. Piumetti, S. Bensaid, L. Veyre, C. Thieuleux, N. Russo, D. Fino, E.A. Quadrelli, R. Pirone, Appl. Catal. B 226 (2018) 147-161.

63. E. Aneggi, C. de Leitenburg, A. Trovarelli, Catal. Today, 181 (2012) 108-115.

64. M. Machida, Y. Murata, K. Kishikawa, D. Zhang, K. Ikeue, Chem.mter. 20 (2008) 4489-4494.

65. E. Aneggi, N.J. Divins, C. de Leitenburg, J. Llorca, J. Catal 312 (2014) 191194.

66. Ll. Soler, A. Casanovas, C. Escudero. V.Pérez-Dieste, E. Aneggi, A. Trovarelli, J. Llorca, ChemCatChem 8 (2016) 2748-2751.

67. H. Wang, B. Jing, H. Wang, N. Ma, W. Liu, D. Weng, X. Wu, S. Liu, Appl. Catal. B 237 (2018) 251-262.

68. A. Bueno-López, K. Krishna, M. Makkee, J.A. J. Catal. 230 (2005) 237-248.

69. M.S. Gross, M.A. Ulla, C.A. Querini, J. Mol.Catal. A, 352 (2012) 86-94. 
Table 1. Main parameters obtained from the textural and structural characterization.

\begin{tabular}{lllll}
\hline Sample & $\begin{array}{l}\mathrm{S}_{\mathrm{BET}} \\
\left(\mathrm{m}^{2} / \mathrm{g}\right)^{\mathrm{a}}\end{array}$ & $\begin{array}{l}\text { Average } \\
\text { crystal size } \\
(\mathrm{nm})^{\mathrm{b}}\end{array}$ & $\begin{array}{l}\mathrm{F}_{2 \mathrm{~g} \text { band }} \\
\text { position } \\
\left(\mathrm{cm}^{-1}\right)^{\mathrm{c}}\end{array}$ & $\begin{array}{l}\text { FWHM of } \mathrm{F}_{2 \mathrm{~g}} \text { band } \\
\left(\mathrm{cm}^{-1}\right)^{\mathrm{c}}\end{array}$ \\
\hline $\mathrm{PrO}_{2}-\mathrm{CP}$ & 28 & 8.6 & 425.0 & - \\
$\mathrm{Ce}_{0.1} \operatorname{Pr}_{0.9} \mathrm{O}_{2}-\mathrm{CP}$ & 15 & 8.2 & 425.0 & 40 \\
$\mathrm{Ce}_{0.2} \mathrm{Pr}_{0.8} \mathrm{O}_{2}-\mathrm{CP}$ & 10 & 9.0 & 442.0 & 48 \\
$\mathrm{Ce}_{0.3} \operatorname{Pr}_{0.7} \mathrm{O}_{2}-\mathrm{CP}$ & 10 & 8.2 & 431.8 & 42 \\
$\mathrm{Ce}_{0.4} \operatorname{Pr}_{0.6} \mathrm{O}_{2}-\mathrm{CP}$ & 11 & 7.0 & 442.0 & 47 \\
$\mathrm{Ce}_{0.5} \operatorname{Pr}_{0.5} \mathrm{O}_{2}-\mathrm{CP}$ & 15 & 7.6 & 445.4 & 42 \\
$\mathrm{Ce}_{0.6} \operatorname{Pr}_{0.4} \mathrm{O}_{2}-\mathrm{CP}$ & 38 & 7.7 & 445.4 & 40 \\
$\mathrm{Ce}_{0.7} \operatorname{Pr}_{0.3} \mathrm{O}_{2}-\mathrm{CP}$ & 62 & 8.2 & 445.4 & 43 \\
$\mathrm{Ce}_{0.8} \operatorname{Pr}_{0.2} \mathrm{O}_{2}-\mathrm{CP}$ & 70 & 8.5 & 448.8 & - \\
\hline $\operatorname{PrO}_{2}-\mathrm{DC}$ & 6 & 11.5 & 428.3 & - \\
$\mathrm{Ce}_{0.1} \operatorname{Pr}_{0.9} \mathrm{O}_{2}-\mathrm{DC}$ & 19 & 10.2 & 431.8 & - \\
$\mathrm{Ce}_{0.2} \operatorname{Pr}_{0.8} \mathrm{O}_{2}-\mathrm{DC}$ & 31 & 11.5 & 431.8 & - \\
$\mathrm{Ce}_{0.3} \operatorname{Pr}_{0.7} \mathrm{O}_{2}-\mathrm{DC}$ & 42 & 12.2 & 438.6 & 46 \\
$\mathrm{Ce}_{0.4} \operatorname{Pr}_{0.6} \mathrm{O}_{2}-\mathrm{DC}$ & 47 & 10.8 & 448.8 & 44 \\
$\mathrm{Ce}_{0.5} \operatorname{Pr}_{0.5} \mathrm{O}_{2}-\mathrm{DC}$ & 44 & 9.8 & 445.4 & 47 \\
$\mathrm{Ce}_{0.6} \operatorname{Pr}_{0.4} \mathrm{O}_{2}-\mathrm{DC}$ & 40 & 10.4 & 445.4 & 41 \\
$\mathrm{Ce}_{0.7} \operatorname{Pr}_{0.3} \mathrm{O}_{2}-\mathrm{DC}$ & 43 & 12.3 & 445.4 & 43 \\
$\mathrm{Ce}_{0.8} \operatorname{Pr}_{0.2} \mathrm{O}_{2}-\mathrm{DC}$ & 45 & 11.2 & 448.8 & 44 \\
\hline
\end{tabular}

${ }^{\text {a }}$ Obtained from $\mathrm{N}_{2}$ physisorption tests at $-196^{\circ} \mathrm{C}$.

${ }^{b}$ Calculated by Scherrer equation from XRD data.

${ }^{c}$ Obtained from Raman data. 
Table 2. Surface atomic ratios estimated by XPS.

\begin{tabular}{|c|c|c|c|c|c|c|c|c|c|}
\hline Sample & $\operatorname{Pr} \%$ & $\mathrm{Ce} \%$ & $\mathrm{O} \%$ & $\mathrm{C} \%$ & $\operatorname{Pr}+3(\%)$ & $\mathrm{Ce}+3(\%)$ & $\mathrm{Ce} / \mathrm{Pr}$ surface & $\mathrm{Ce} / \mathrm{Pr}$ nominal & $\mathrm{O} /(\mathrm{Ce}+\mathrm{Pr})$ \\
\hline $\mathrm{PrO}_{2}-\mathrm{CP}$ & 18.7 & - & 50.4 & 30.5 & 65.1 & 0.00 & 0.000 & 0.000 & 2.69 \\
\hline $\mathrm{Ce}_{0.1} \operatorname{Pr}_{0.9} \mathrm{O}_{2}-\mathrm{CP}$ & 18.8 & 1.6 & 50.7 & 28.3 & 51.9 & 30.5 & 0.085 & 0.111 & 2.48 \\
\hline $\mathrm{Ce}_{0.2} \mathrm{Pr}_{0.8} \mathrm{O}_{2}-\mathrm{CP}$ & 17.0 & 3.4 & 48.3 & 30.4 & 30.8 & 33.1 & 0.200 & 0.245 & 2.38 \\
\hline $\mathrm{Ce}_{0.3} \mathrm{Pr}_{0.7} \mathrm{O}_{2}-\mathrm{CP}$ & 14.7 & 4.9 & 49.6 & 30.0 & 44.1 & 31.8 & 0.333 & 0.428 & 2.54 \\
\hline $\mathrm{Ce}_{0.4} \operatorname{Pr}_{0.6} \mathrm{O}_{2}-\mathrm{CP}$ & 13.8 & 6.8 & 49.6 & 29.1 & 53.8 & 34.5 & 0.493 & 0.662 & 2.41 \\
\hline $\mathrm{Ce}_{0.5} \mathrm{Pr}_{0.5} \mathrm{O}_{2}-\mathrm{CP}$ & 9.2 & 6.4 & 40.8 & 43.0 & 52.7 & 30.9 & 0.696 & 0.995 & 2.62 \\
\hline $\mathrm{Ce}_{0.6} \mathrm{Pr}_{0.4} \mathrm{O}_{2}-\mathrm{CP}$ & 10.3 & 10.8 & 49.5 & 28.3 & 47.9 & 33.1 & 1.049 & 1.504 & 2.34 \\
\hline $\mathrm{Ce}_{0.7} \mathrm{Pr}_{0.3} \mathrm{O}_{2}-\mathrm{CP}$ & 6.7 & 11.0 & 43.8 & 37.6 & 45.6 & 30.2 & 1.642 & 2.318 & 2.48 \\
\hline $\mathrm{Ce}_{0.8} \mathrm{Pr}_{0.2} \mathrm{O}_{2}-\mathrm{CP}$ & 6.3 & 15.6 & 53.3 & 24.8 & 74.7 & 30.9 & 2.476 & 3.988 & 2.44 \\
\hline $\mathrm{PrO}_{2}-\mathrm{DC}$ & 13.6 & - & 42.8 & 43.1 & 44.7 & 0.00 & 0.000 & 0.000 & 3.14 \\
\hline $\mathrm{Ce}_{0.1} \operatorname{Pr}_{0.9} \mathrm{O}_{2}-\mathrm{DC}$ & 15.7 & 2.0 & 47.4 & 34.9 & 46.3 & 30.0 & 0.127 & 0.127 & 2.67 \\
\hline $\mathrm{Ce}_{0.2} \mathrm{Pr}_{0.8} \mathrm{O}_{2}-\mathrm{DC}$ & 14.9 & 3.5 & 47.1 & 33.9 & 44.9 & 34.1 & 0.236 & 0.236 & 2.56 \\
\hline $\mathrm{Ce}_{0.3} \operatorname{Pr}_{0.7} \mathrm{O}_{2}-\mathrm{DC}$ & 13.4 & 3.5 & 48.6 & 34.6 & 48.3 & 31.1 & 0.262 & 0.433 & 2.88 \\
\hline $\mathrm{Ce}_{0.4} \mathrm{Pr}_{0.6} \mathrm{O}_{2}-\mathrm{DC}$ & 11.3 & 5.8 & 46.2 & 35.5 & 43.2 & 32.2 & 0.513 & 0.674 & 2.69 \\
\hline $\mathrm{Ce}_{0.5} \operatorname{Pr}_{0.5} \mathrm{O}_{2}-\mathrm{DC}$ & 13.8 & 8.4 & 45.1 & 32.5 & 44.8 & 33.4 & 0.609 & 1.000 & 2.03 \\
\hline $\mathrm{Ce}_{0.6} \operatorname{Pr}_{0.4} \mathrm{O}_{2}-\mathrm{DC}$ & 9.0 & 8.6 & 46.2 & 35.1 & 49.0 & 33.5 & 0.956 & 1.508 & 2.64 \\
\hline $\mathrm{Ce}_{0.7} \operatorname{Pr}_{0.3} \mathrm{O}_{2}-\mathrm{DC}$ & 8.4 & 11.8 & 46.8 & 32.1 & 32.4 & 31.5 & 1.408 & 2.343 & 2.31 \\
\hline $\mathrm{Ce}_{0.8} \operatorname{Pr}_{0.2} \mathrm{O}_{2}-\mathrm{DC}$ & 6.7 & 12.4 & 42.3 & 37.8 & 46.8 & 33.6 & 1.862 & 4.000 & 2.22 \\
\hline
\end{tabular}


Table 3. Parameters calculated from ceria-praseodymia mixed oxides measured from TPD runs.

\begin{tabular}{llllll}
\hline Sample & $\begin{array}{l}\mathrm{O}_{2} \text { emitted } \\
\left(\mu \mathrm{mol} / \mathrm{g}_{\text {cat }}\right)\end{array}$ & $\begin{array}{l}\text { \% Ln reduced } \\
(\mathrm{Ce} \text { and } \mathrm{Pr})\end{array}$ & $\%$ Pr reduced & $\delta$ & $\begin{array}{l}\text { Monolayers } \\
\text { reduced }\end{array}$ \\
\hline $\mathrm{PrO}_{2}-\mathrm{CP}$ & 913 & 63.2 & 63.2 & 0.316 & 9.8 \\
$\mathrm{Ce}_{0.1} \operatorname{Pr}_{0.9} \mathrm{O}_{2}-\mathrm{CP}$ & 671 & 46.1 & 51.3 & 0.231 & 13.6 \\
$\mathrm{Ce}_{0.2} \operatorname{Pr}_{0.8} \mathrm{O}_{2}-\mathrm{CP}$ & 735 & 49.7 & 62.2 & 0.249 & 22.7 \\
$\mathrm{Ce}_{0.3} \operatorname{Pr}_{0.7} \mathrm{O}_{2}-\mathrm{CP}$ & 615 & 42.3 & 60.4 & 0.211 & 18.7 \\
$\mathrm{Ce}_{0.4} \operatorname{Pr}_{0.6} \mathrm{O}_{2}-\mathrm{CP}$ & 602 & 41.4 & 68.9 & 0.207 & 17.1 \\
$\mathrm{Ce}_{0.5} \operatorname{Pr}_{0.5} \mathrm{O}_{2}-\mathrm{CP}$ & 457 & 31.5 & 63.1 & 0.158 & 9.0 \\
$\mathrm{Ce}_{0.6} \operatorname{Pr}_{0.4} \mathrm{O}_{2}-\mathrm{CP}$ & 388 & 26.7 & 66.8 & 0.134 & 3.1 \\
$\mathrm{Ce}_{0.7} \operatorname{Pr}_{0.3} \mathrm{O}_{2}-\mathrm{CP}$ & 259 & 17.8 & 59.4 & 0.089 & 1.3 \\
$\mathrm{Ce}_{0.8} \operatorname{Pr}_{0.2} \mathrm{O}_{2}-\mathrm{CP}$ & 141 & 9.7 & 48.5 & 0.048 & 0.6 \\
\hline $\operatorname{PrO}_{2}-\mathrm{DC}$ & 1054 & 72.9 & 72.9 & 0.364 & 57.7 \\
$\mathrm{Ce}_{0.1} \operatorname{Pr}_{0.9} \mathrm{O}_{2}-\mathrm{DC}$ & 764 & 52.5 & 58.3 & 0.263 & 12.4 \\
$\mathrm{Ce}_{0.2} \operatorname{Pr}_{0.8} \mathrm{O}_{2}-\mathrm{DC}$ & 745 & 51.2 & 64.0 & 0.256 & 7.4 \\
$\mathrm{Ce}_{0.3} \operatorname{Pr}_{0.7} \mathrm{O}_{2}-\mathrm{DC}$ & 671 & 46.1 & 65.9 & 0.231 & 4.9 \\
$\mathrm{Ce}_{0.4} \operatorname{Pr}_{0.6} \mathrm{O}_{2}-\mathrm{DC}$ & 624 & 42.9 & 71.5 & 0.214 & 4.1 \\
$\mathrm{Ce}_{0.5} \operatorname{Pr}_{0.5} \mathrm{O}_{2}-\mathrm{DC}$ & 591 & 40.8 & 81.6 & 0.204 & 4.1 \\
$\mathrm{Ce}_{0.6} \operatorname{Pr}_{0.4} \mathrm{O}_{2}-\mathrm{DC}$ & 433 & 29.7 & 74.3 & 0.149 & 3.3 \\
$\mathrm{Ce}_{0.7} \operatorname{Pr}_{0.3} \mathrm{O}_{2}-\mathrm{DC}$ & 361 & 24.7 & 82.4 & 0.124 & 2.6 \\
$\mathrm{Ce}_{0.8} \operatorname{Pr}_{0.2} \mathrm{O}_{2}-\mathrm{DC}$ & 204 & 14.1 & 70.5 & 0.071 & 1.4 \\
\hline
\end{tabular}


Table 4. Quantifications estimated from catalytic performances towards soot combustion for all the catalysts investigated.

(Quantified values up to $500^{\circ} \mathrm{C}$ between parentheses).

\begin{tabular}{|c|c|c|c|c|c|c|c|c|c|c|}
\hline \multirow[t]{3}{*}{ Sample } & \multicolumn{5}{|c|}{ Co-precipitation method } & \multicolumn{5}{|c|}{ Direct calcination method } \\
\hline & \multicolumn{2}{|c|}{ Loose contact } & \multicolumn{3}{|c|}{ Tight contact } & \multicolumn{2}{|c|}{ Loose contact } & \multicolumn{3}{|c|}{ Tight contact } \\
\hline & $\mu \mathrm{mol} \mathrm{O} / \mathrm{g}_{\text {cat }}$ & $\mu \mathrm{mol} \mathrm{CO} 2 / \mathrm{g}_{\mathrm{cat}}$ & $\mu \mathrm{mol} \mathrm{O} / \mathrm{g}_{\mathrm{cat}}$ & $\mu \mathrm{mol} \mathrm{CO} / \mathrm{g}_{\mathrm{cat}}$ & $\mu \mathrm{mol} \mathrm{CO} 2 / \mathrm{g}_{\mathrm{cat}}$ & $\mu \mathrm{mol} \mathrm{O} / \mathrm{g}_{\mathrm{cat}}$ & $\mu \mathrm{mol} \mathrm{CO} 2 / \mathrm{g}_{\text {cat }}$ & $\mu \mathrm{mol} \mathrm{O} / \mathrm{g}_{\mathrm{cat}}$ & $\mu \mathrm{mol} \mathrm{CO} / \mathrm{g}_{\text {cat }}$ & $\mu \mathrm{mol} \mathrm{CO} 2 / \mathrm{g}_{\text {cat }}$ \\
\hline $\mathrm{PrO}_{2}$ & $756(53)$ & $637(35)$ & - & - & - & $835(133)$ & $828(64)$ & $1012(37)$ & $144(0)$ & $1038(691)$ \\
\hline $\mathrm{Ce}_{0.1} \mathrm{Pr}_{0.9} \mathrm{O}_{2}$ & $557(175)$ & $660(157)$ & $635(33)$ & $69(0)$ & $947(771)$ & 609 (119) & $797(179)$ & - & - & - \\
\hline $\mathrm{Ce}_{0.2} \mathrm{Pr}_{0.8} \mathrm{O}_{2}$ & 455 (99) & $605(90)$ & $694(65)$ & $229(0)$ & $966(699)$ & $590(177)$ & $586(167)$ & - & - & - \\
\hline $\mathrm{Ce}_{0.3} \operatorname{Pr}_{0.7} \mathrm{O}_{2}$ & $461(184)$ & $432(118)$ & - & - & - & $505(183)$ & $558(194)$ & - & - & - \\
\hline $\mathrm{Ce}_{0.4} \mathrm{Pr}_{0.6} \mathrm{O}_{2}$ & $385(153)$ & $299(47)$ & $576(22)$ & $267(0)$ & $597(415)$ & $398(135)$ & $481(97)$ & $607(14)$ & $298(0)$ & $677(578)$ \\
\hline $\mathrm{Ce}_{0.5} \operatorname{Pr}_{0.5} \mathrm{O}_{2}$ & $327(121)$ & 386 (97) & - & - & - & 448 (186) & 344 (114) & - & - & - \\
\hline $\mathrm{Ce}_{0.6} \operatorname{Pr}_{0.4} \mathrm{O}_{2}$ & $318(162)$ & $279(101)$ & - & - & - & $370(180)$ & 355 (169) & - & - & - \\
\hline $\mathrm{Ce}_{0.7} \mathrm{Pr}_{0.3} \mathrm{O}_{2}$ & $210(109)$ & $345(129)$ & - & - & - & 334 (164) & $343(157)$ & $350(7)$ & $260(0)$ & $396(270)$ \\
\hline
\end{tabular}

NOTE: the parameter $\mu \mathrm{mol} \mathrm{O}_{2} / \mathrm{g}_{\mathrm{cat}}$ refers to the amounts consumed during the soot combustion process. 


\section{Captions to the Figures}

Figure 1. XRD patterns of the different catalysts obtained by: a) co-precipitation and b) direct calcination.

(At the bottom of the figures appear the representative reference XRD patterns of $\mathrm{CeO}_{2}$, $\mathrm{PrO}_{2}, \mathrm{PrO}_{1.83}$ and $\left.\mathrm{Pr}_{6} \mathrm{O}_{11}\right)$.

Figure 2. Variation of cell parameter with $\mathrm{x}$ for $\mathrm{Ce}_{1-\mathrm{x}} \mathrm{Pr}_{\mathrm{x}} \mathrm{O}_{2}$ formulations (x parameter represented as $\operatorname{Pr} /(\mathrm{Ce}+\mathrm{Pr}))$. Dotted lines: calculated by using Vegard's law for solid solutions between the dioxides of cerium and praseodymium and for $\mathrm{CeO}_{2}-\mathrm{PrO}_{1.83}$, respectively.

Figure 3. Variation of a) BET surface area and b) pore volume versus Pr content for $\mathrm{Ce}_{1-}$ ${ }_{x} \operatorname{Pr}_{\mathrm{x}} \mathrm{O}_{2}$ synthesized formulations.

Figure 4. Pore size distribution for the catalysts obtained by: a) co-precipitation and b) direct calcination.

Figure 5. Raman spectra of the different catalyst obtained by: a) direct calcination and b) co-precipitation.

Figure 6. Relationship between the $\mathrm{I}_{\mathrm{vacancies} \mathrm{band}} / \mathrm{I}_{\mathrm{F} 2 \mathrm{~g}}$, obtained from Raman spectroscopy, and the Pr content of the catalysts.

Figure 7. XPS data plotted as: a) Ce/Pr surface values versus nominal values and b) the ratio of $\mathrm{Ce} / \mathrm{Pr}$ nominal and $\mathrm{Ce} / \mathrm{Pr}$ surface values versus Pr content.

(The continuous black line, presents in both graphs, represents the theoretical homogeneous distribution of cerium and praseodymium on the surface)

Figure 8. Oxygen profiles during TPD under inert atmosphere for samples obtained by a) co-precipitation method and b) direct calcination method (where $\mathrm{x}$ is related to $\mathrm{Ce}_{1-\mathrm{x}} \mathrm{Pr}_{\mathrm{x}} \mathrm{O}_{2}$ formula). 
Figure 9. Correlations among total $\mathrm{O}_{2}$ emitted and Pr content for: a) co-precipitation samples and b) direct calcination samples.

Figure 10. Correlations among $\mathrm{O}_{2}$ emitted up to $500^{\circ} \mathrm{C}$ and $\mathrm{Pr}$ content for the catalysts investigated.

(Ce/Pr surface atomic ratios included to check that higher values of $\mathrm{O}_{2}$ emission always correspond to more surface-enriched Pr samples).

Figure 11. $\mathrm{CO}_{2}$ and $\mathrm{O}_{2}$ emission profiles obtained during the soot combustion experiments under inert atmosphere in loose contact mode for direct calcination samples:

a) $\mathrm{PrO}_{2}$; b) $\mathrm{Ce}_{0.1} \operatorname{Pr}_{0.9} \mathrm{O}_{2}$; c) $\mathrm{Ce}_{0.2} \mathrm{Pr}_{0.8} \mathrm{O}_{2}$; d) $\mathrm{Ce}_{0.3} \operatorname{Pr}_{0.7} \mathrm{O}_{2}$; e) $\mathrm{Ce}_{0.4} \operatorname{Pr}_{0.6} \mathrm{O}_{2}$; f) $\mathrm{Ce}_{0.5} \operatorname{Pr}_{0.5} \mathrm{O}_{2}$; g) $\mathrm{Ce}_{0.6} \mathrm{Pr}_{0.4} \mathrm{O}_{2}$; and h) $\mathrm{Ce}_{0.7} \mathrm{Pr}_{0.3} \mathrm{O}_{2}$.

$\left(\mathrm{O}_{2}\right.$ emitted during the $\mathrm{O}_{2}$-TPD of the corresponding catalyst is represented in dotted line for comparison purpose).

Figure 12. $\mathrm{CO}_{2}, \mathrm{CO}$ and $\mathrm{O}_{2}$ emission profiles obtained during the soot combustion experiments under inert atmosphere in tight contact mode for: a) $\mathrm{PrO}_{2}-\mathrm{CN}$; b) $\mathrm{Ce}_{0.1} \mathrm{Pr}_{0.9} \mathrm{O}_{2}-\mathrm{CP}$; c) $\mathrm{Ce}_{0.2} \mathrm{Pr}_{0.8} \mathrm{O}_{2}-\mathrm{CP}$; d) $\mathrm{Ce}_{0.4} \operatorname{Pr}_{0.6} \mathrm{O}_{2}-\mathrm{CP}$; e) $\mathrm{Ce}_{0.4} \operatorname{Pr}_{0.6} \mathrm{O}_{2}-\mathrm{CN}$; and $\mathrm{f}$ ) $\mathrm{Ce}_{0.7} \operatorname{Pr}_{0.3} \mathrm{O}_{2}-\mathrm{CN}$.

$\left(\mathrm{O}_{2}\right.$ emitted during the $\mathrm{O}_{2}$-TPD of the corresponding catalyst is represented in dotted line for comparison purpose).

Figure 13. Soot combustion (\%) under inert atmosphere for ceria-praseodymia oxides as function of Pr content for selected catalysts (numbers on bars reflect BET surface areas of the corresponding catalysts). 

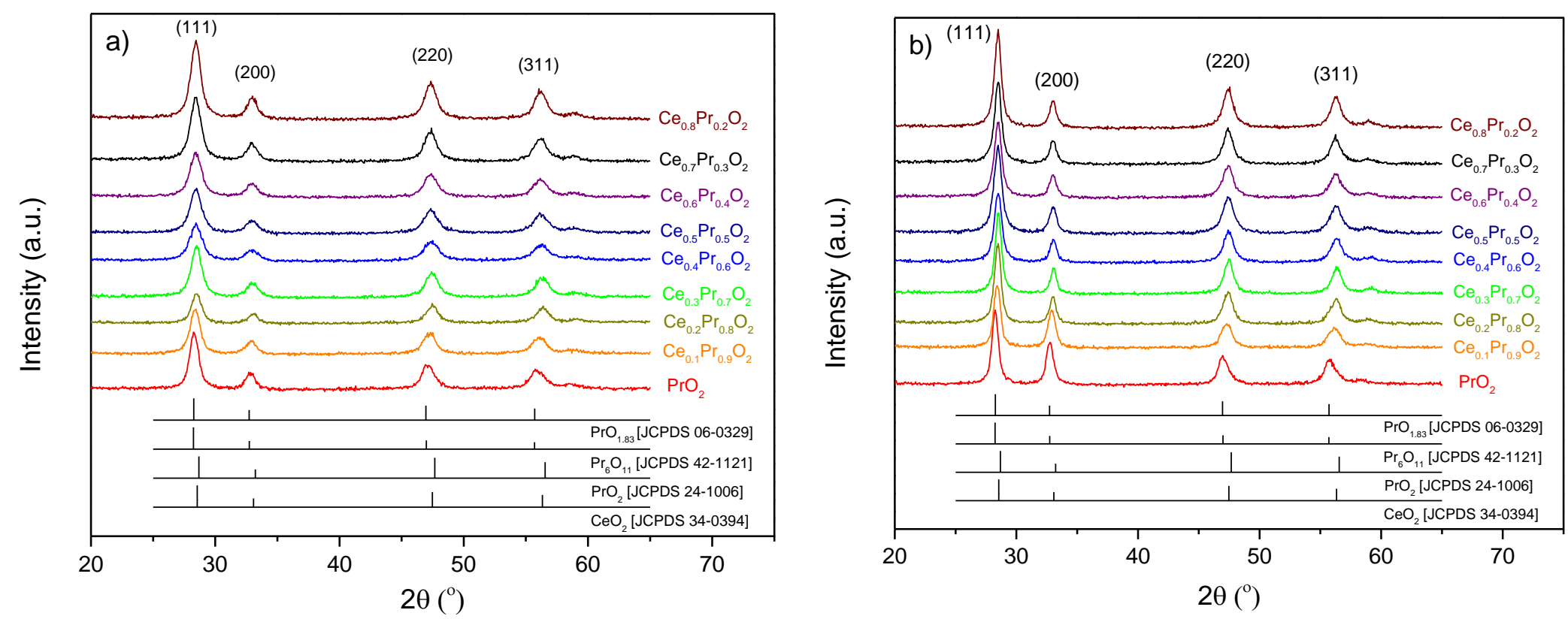

Fig. 1. XRD patterns of the different catalysts obtained by: a) co-precipitation and b) direct calcination.

(At the bottom of the figures appear the representative reference XRD patterns of $\mathrm{CeO}_{2}, \mathrm{PrO}_{2}, \mathrm{PrO}_{1.83}$ and $\operatorname{Pr}_{6} \mathrm{O}_{11}$ ). 



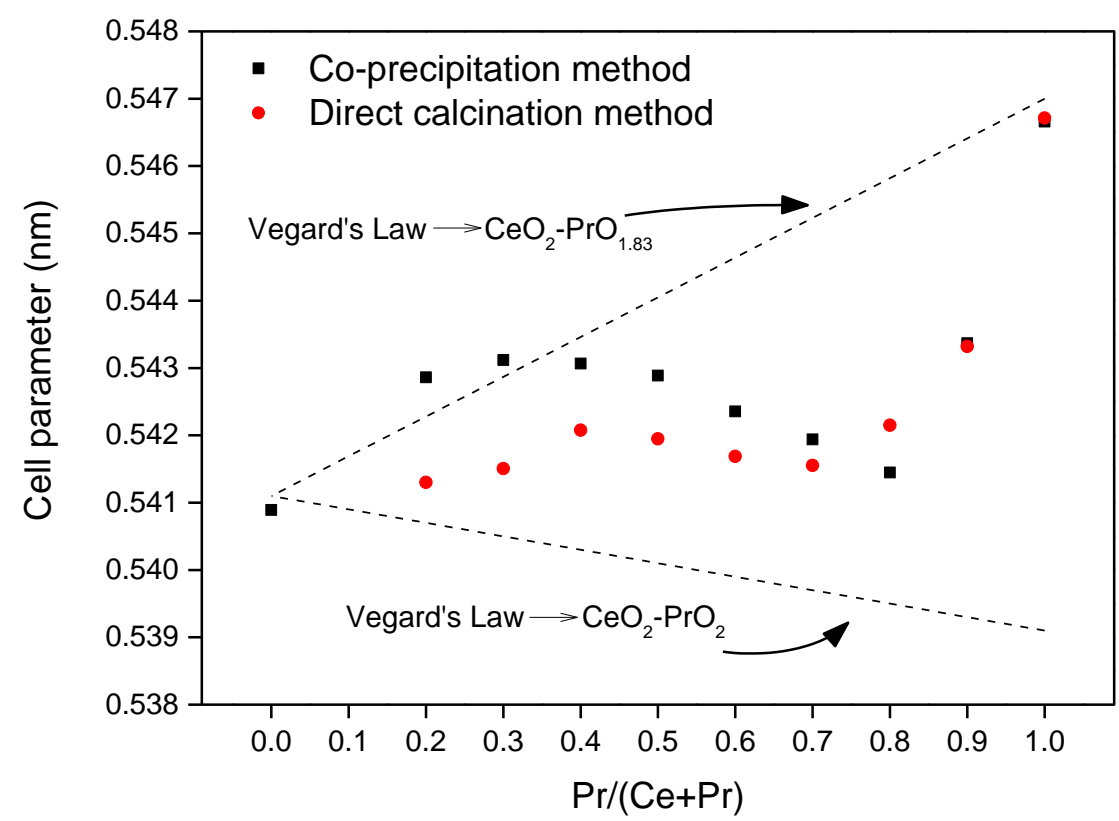

Fig. 2. Variation of cell parameter with $\mathrm{x}$ for $\mathrm{Ce}_{1-\mathrm{x}} \mathrm{Pr}_{\mathrm{x}} \mathrm{O}_{2}$ formulations (x parameter represented as $\mathrm{Pr} /(\mathrm{Ce}+\mathrm{Pr})$ ). Dotted lines: calculated by using Vegard's law for solid solutions between the dioxides of cerium and praseodymium and for $\mathrm{CeO}_{2}-\mathrm{PrO}_{1.83}$, respectively. 


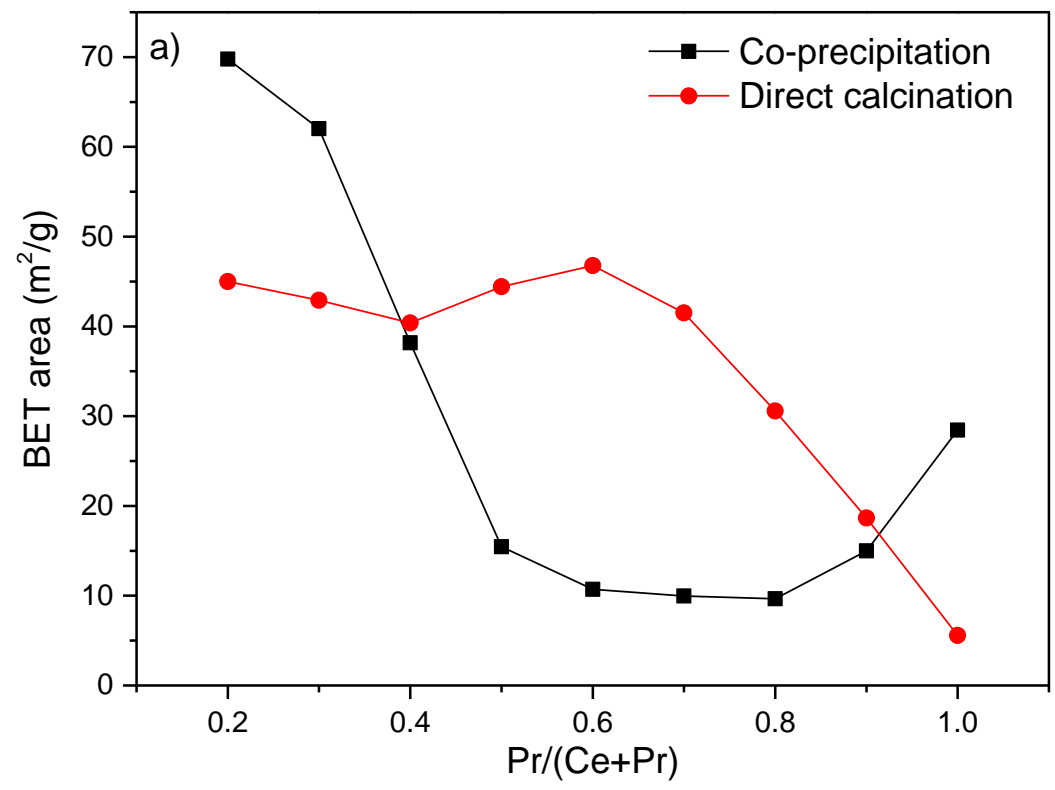

Fig. 3. Variation of a) BET surface area and b) pore volume versus $\operatorname{Pr}$ content for $\mathrm{Ce}_{1-\mathrm{x}} \mathrm{Pr}_{\mathrm{x}} \mathrm{O}_{2}$ synthesized formulations. 


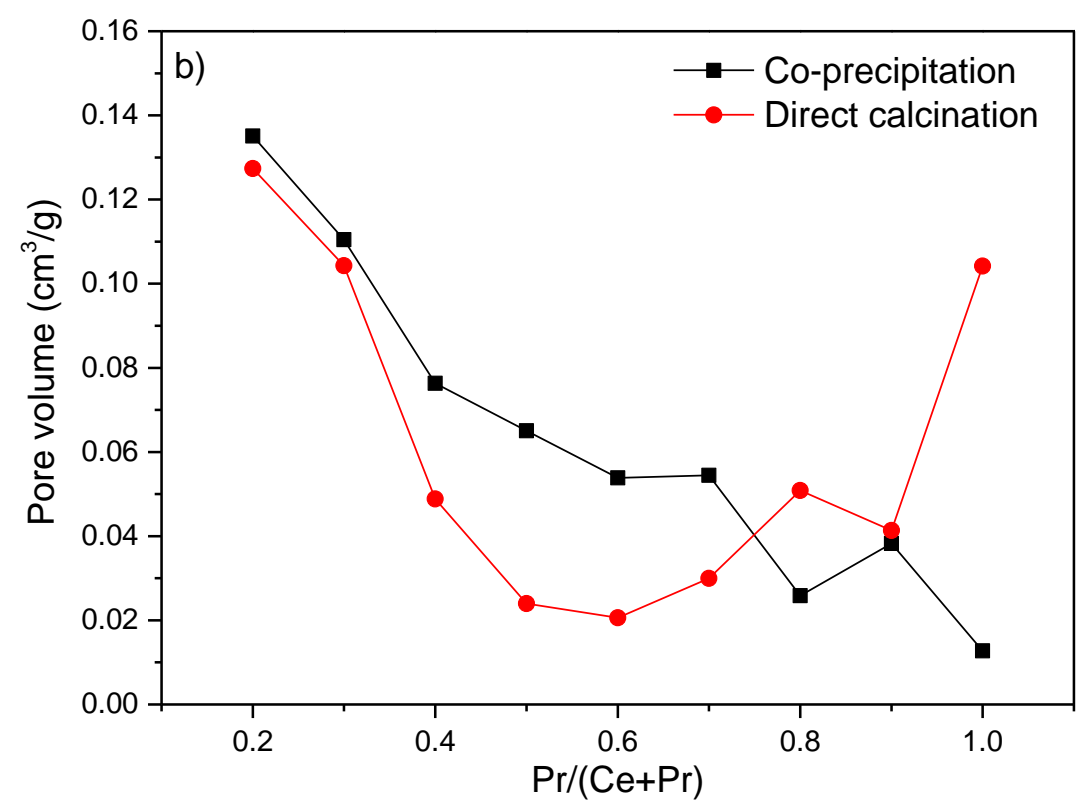

Fig. 3. Variation of a) BET surface area and b) pore volume versus $\operatorname{Pr}$ content for $\mathrm{Ce}_{1-\mathrm{x}} \mathrm{Pr}_{\mathrm{x}} \mathrm{O}_{2}$ synthesized formulations. 


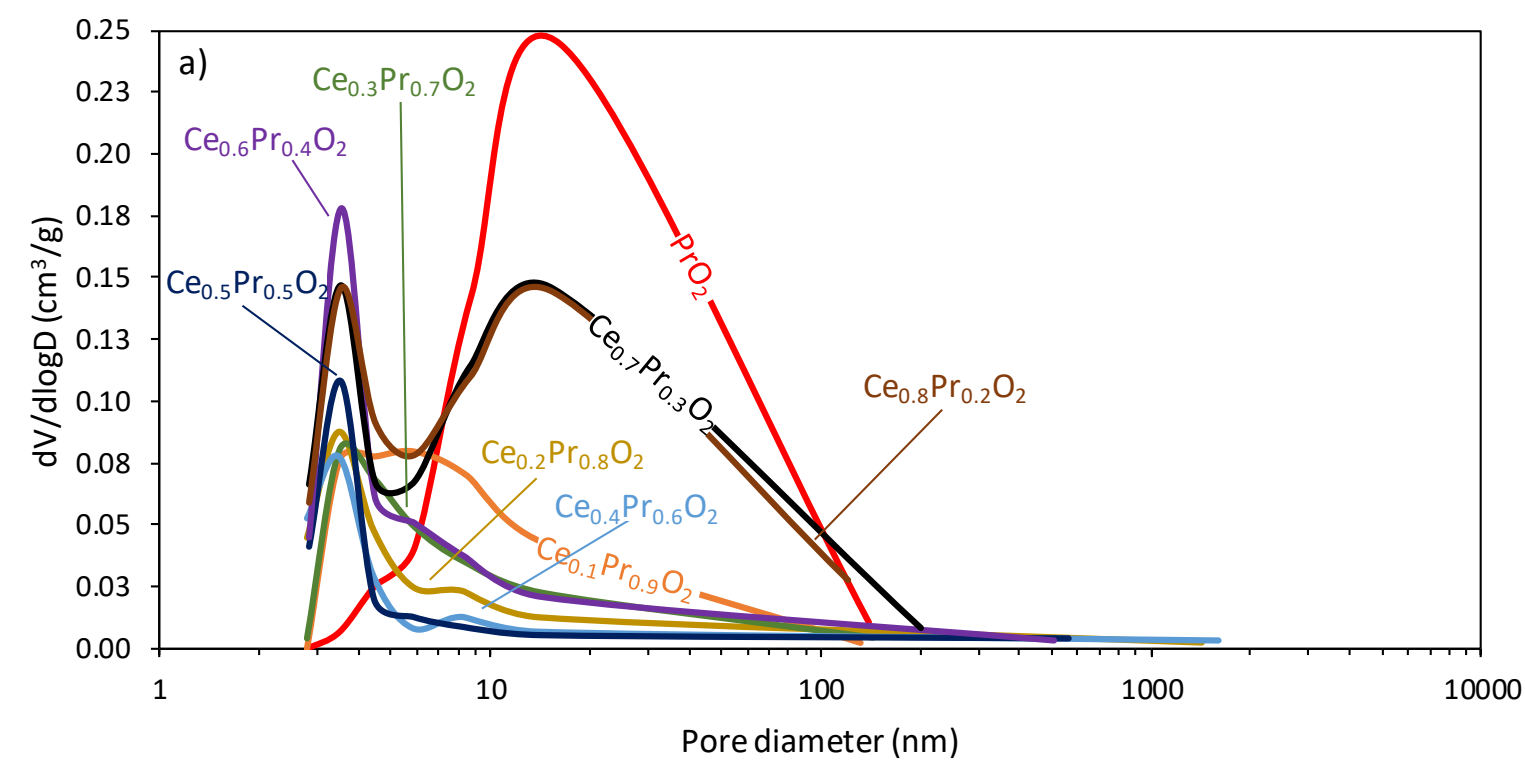

Fig. 4. Pore size distribution for the catalysts obtained by: a) co-precipitation and b) direct calcination. 


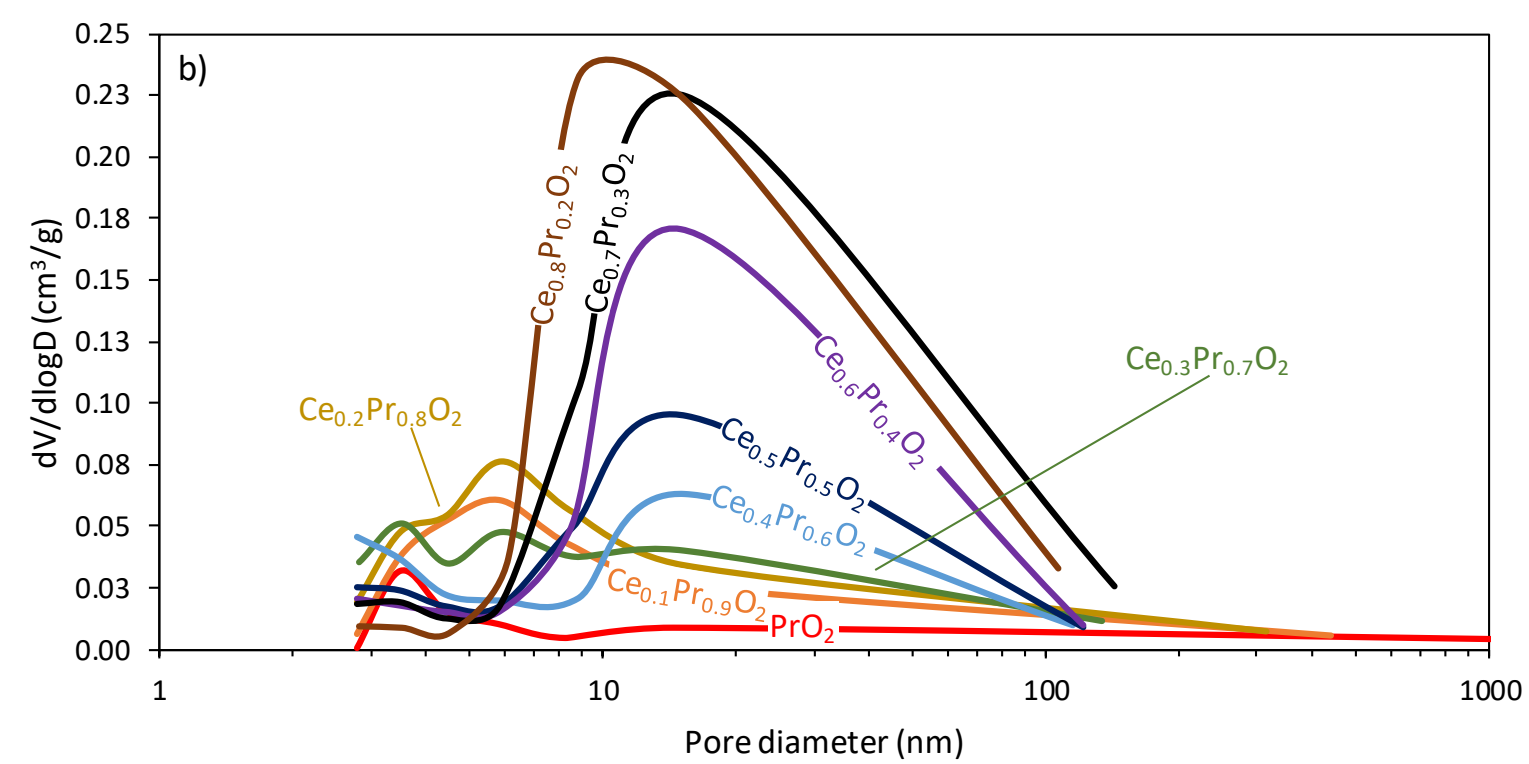

Fig. 4. Pore size distribution for the catalysts obtained by: a) co-precipitation and b) direct calcination. 


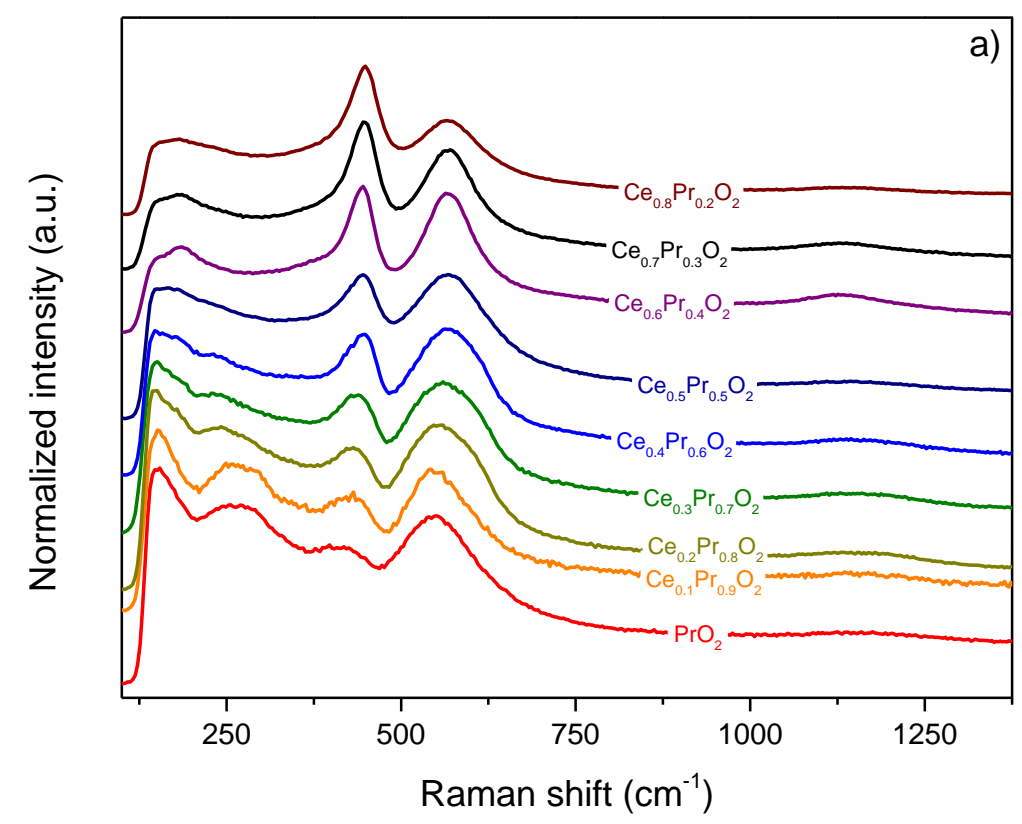

Fig. 5. Raman spectra of the different catalyst obtained by: a) direct calcination and b) co-precipitation. 


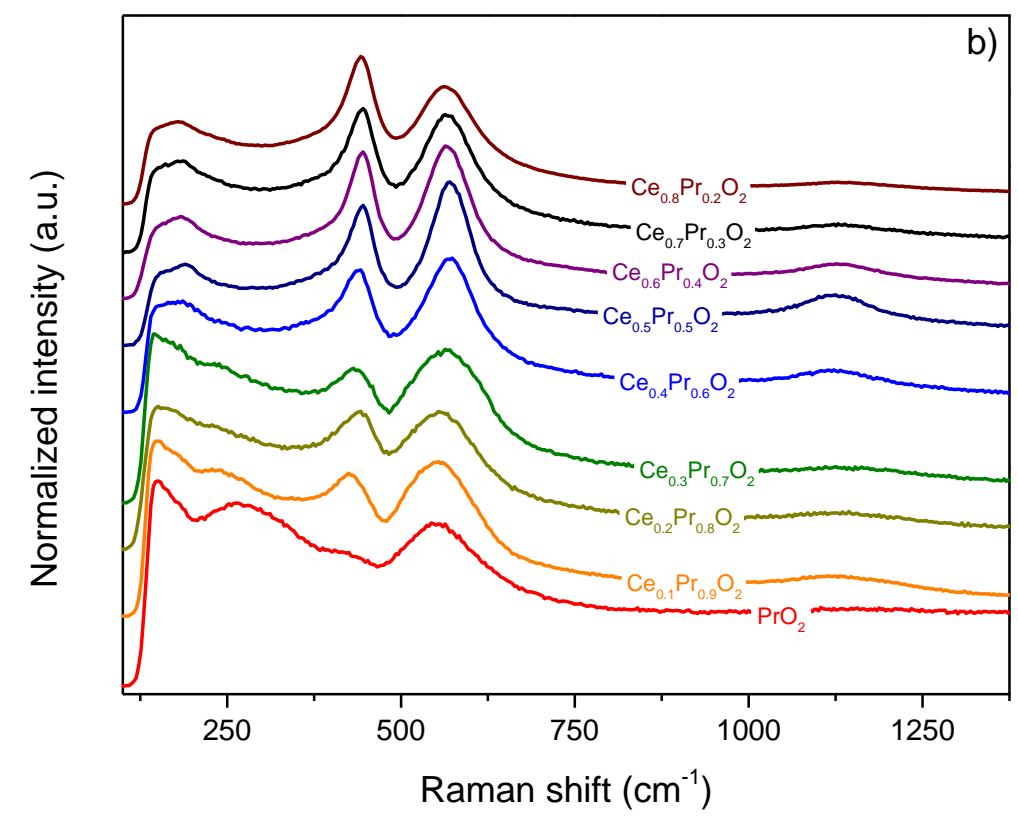

Fig. 5. Raman spectra of the different catalyst obtained by: a) direct calcination and b) co-precipitation. 


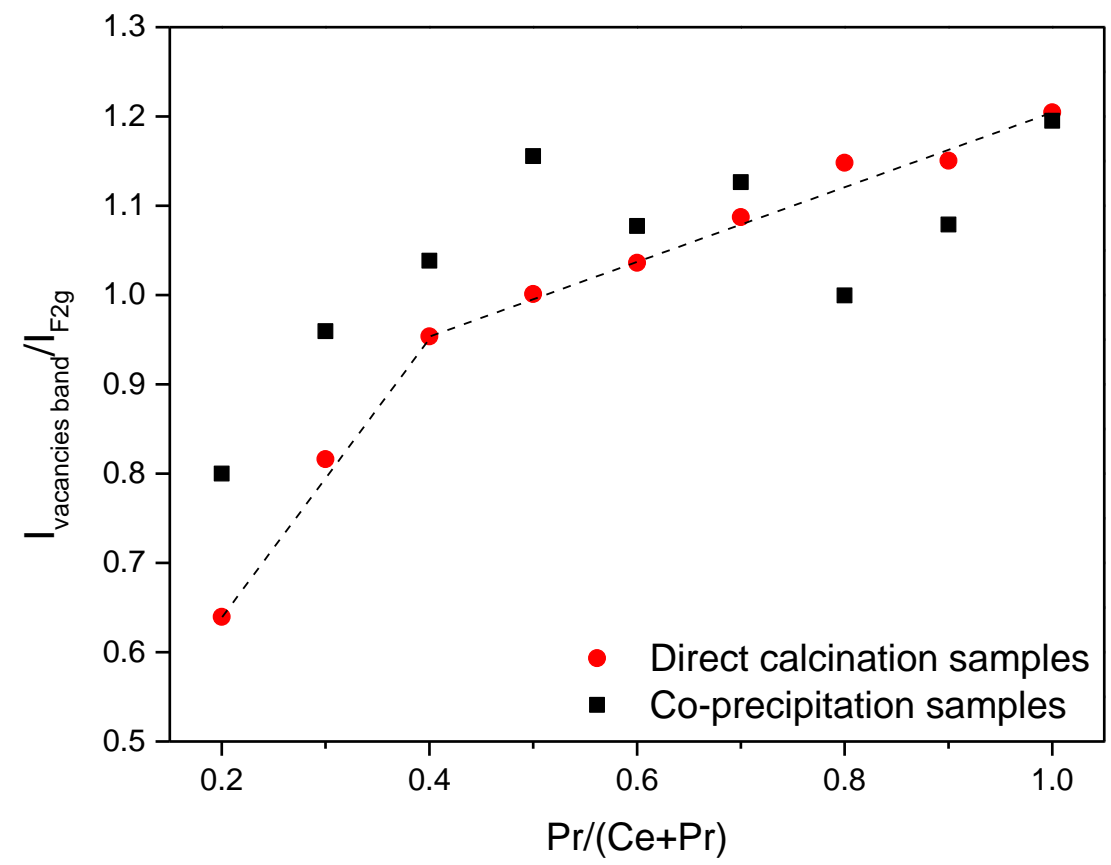

Fig. 6. Relationship between the $\mathrm{I}_{\mathrm{vacancies} \mathrm{band}} / \mathrm{I}_{\mathrm{F} 2 \mathrm{~g}}$, obtained from Raman spectroscopy, and the $\operatorname{Pr}$ content of the catalysts. 

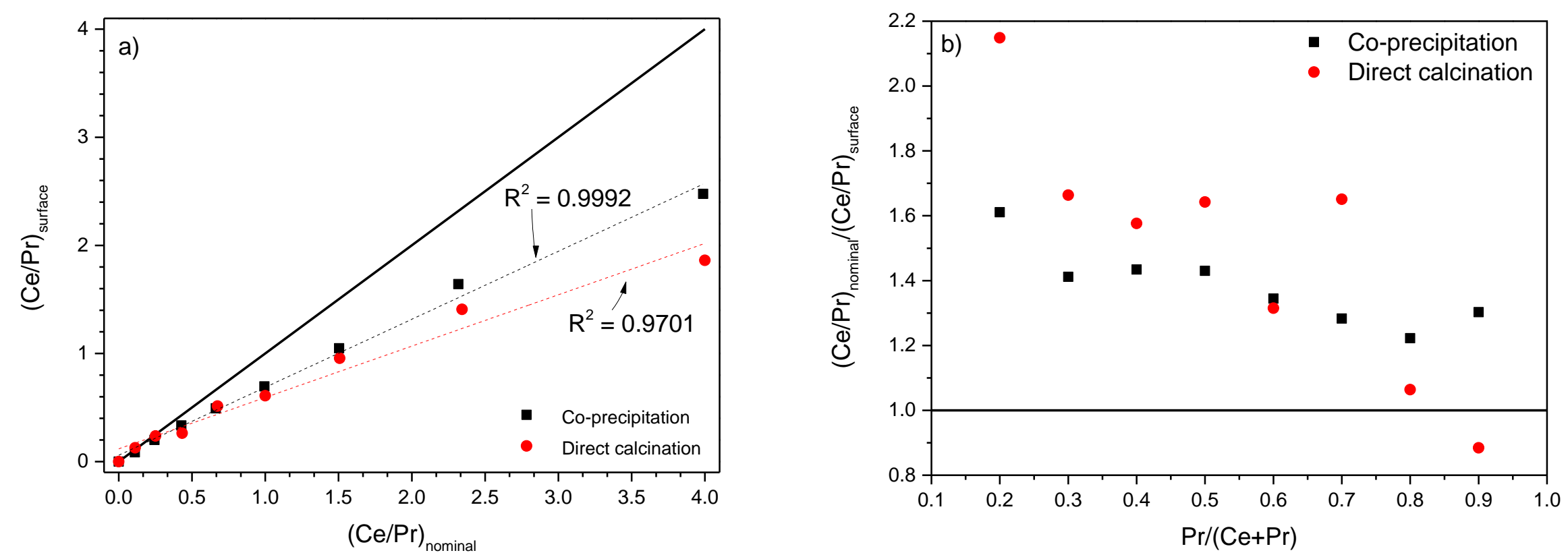

Fig. 7. XPS data plotted as: a) Ce/Pr surface values versus nominal values and b) the ratio of $\mathrm{Ce} / \mathrm{Pr}$ nominal and Ce/Pr surface values versus Pr content.

(The continuous black line, presents in both graphs, represents the theoretical homogeneous distribution of cerium and praseodymium on the surface). 

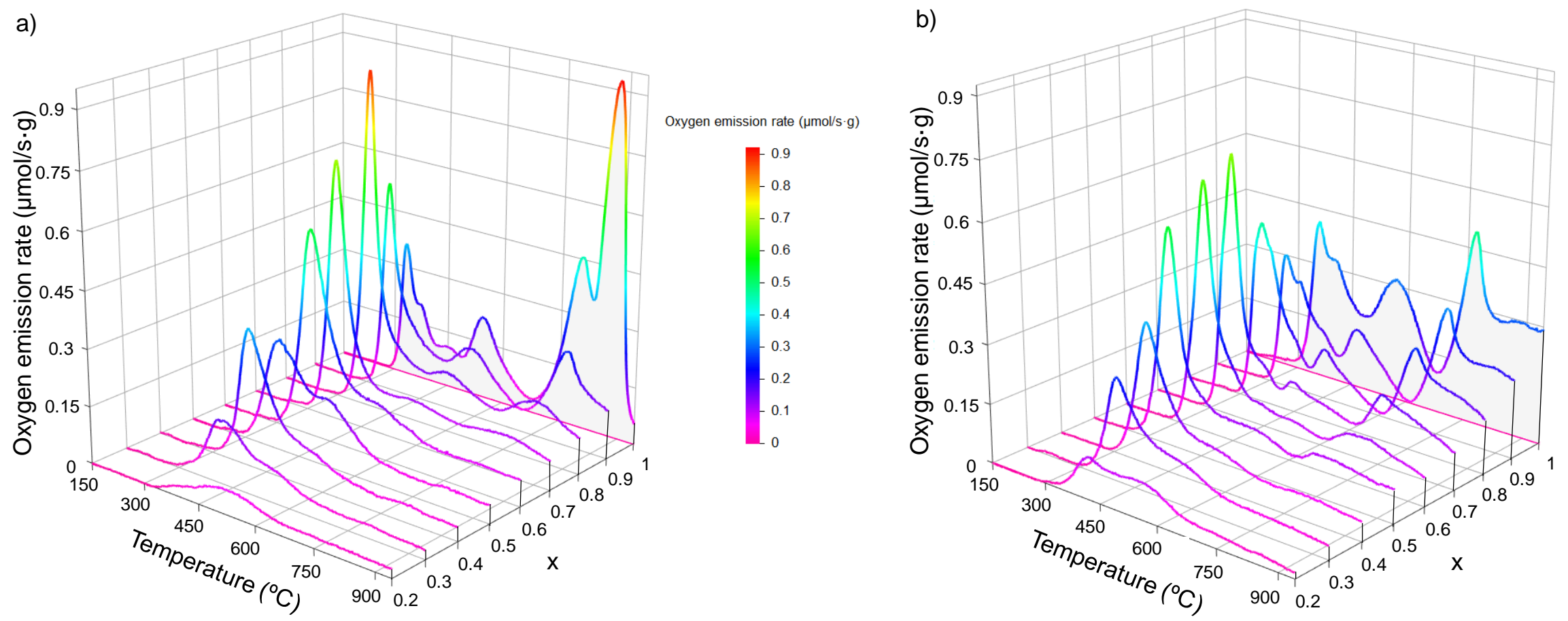

Fig. 8. Oxygen profiles during TPD under inert atmosphere for samples obtained by a) co-precipitation method and b) direct calcination method (where $\mathrm{x}$ is related to $\mathrm{Ce}_{1-\mathrm{x}} \mathrm{Pr}_{\mathrm{x}} \mathrm{O}_{2}$ formula). 

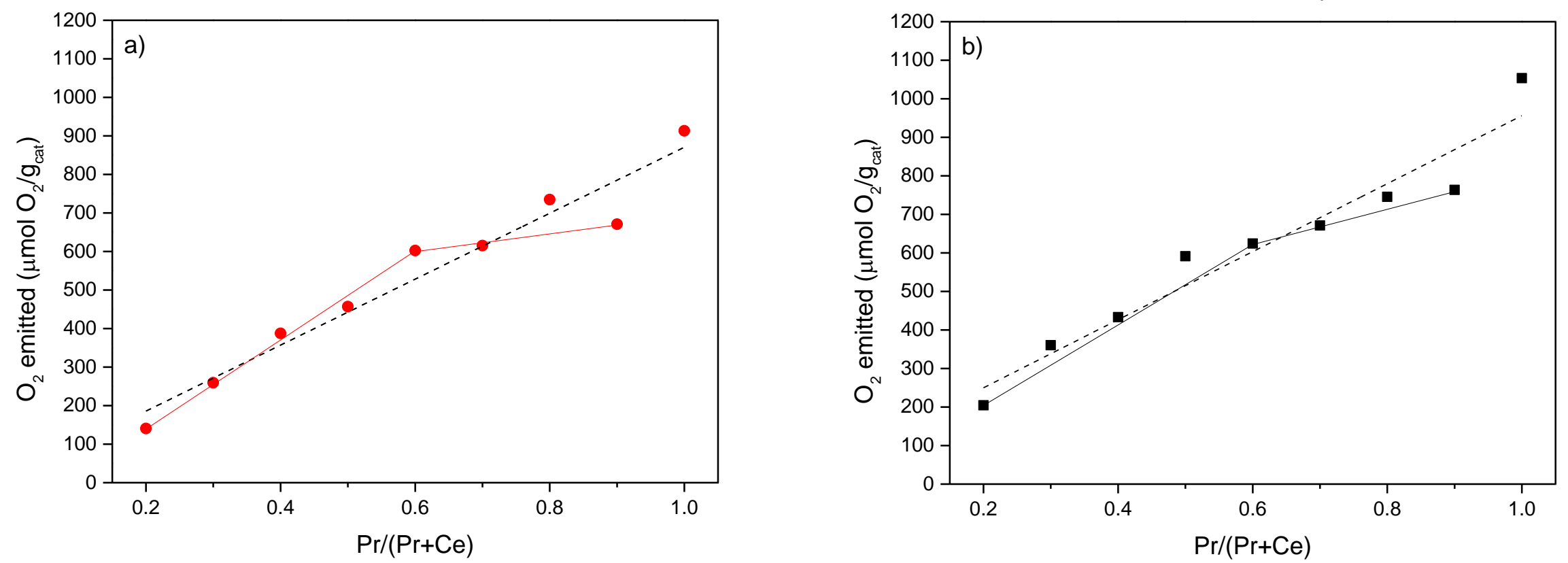

Fig. 9. Correlations among total $\mathrm{O}_{2}$ emitted and $\mathrm{Pr}$ content for: a) co-precipitation samples and b) direct calcination samples. 


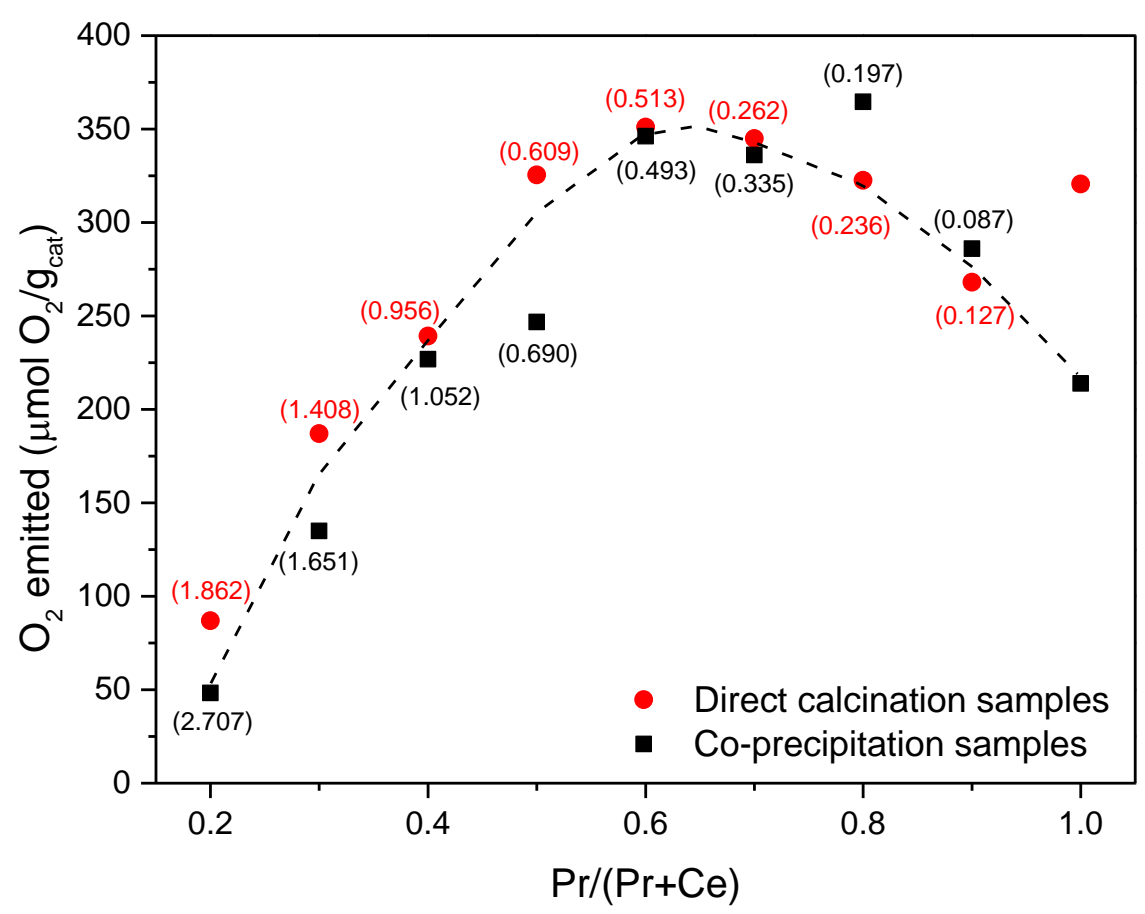

Fig. 10. Correlations among $\mathrm{O}_{2}$ emitted up to $500^{\circ} \mathrm{C}$ and $\operatorname{Pr}$ content for the catalysts investigated.

(Ce/Pr surface atomic ratios included to check that higher values of $\mathrm{O}_{2}$ emission always correspond to more surface-enriched $\mathrm{Pr}$ samples). 

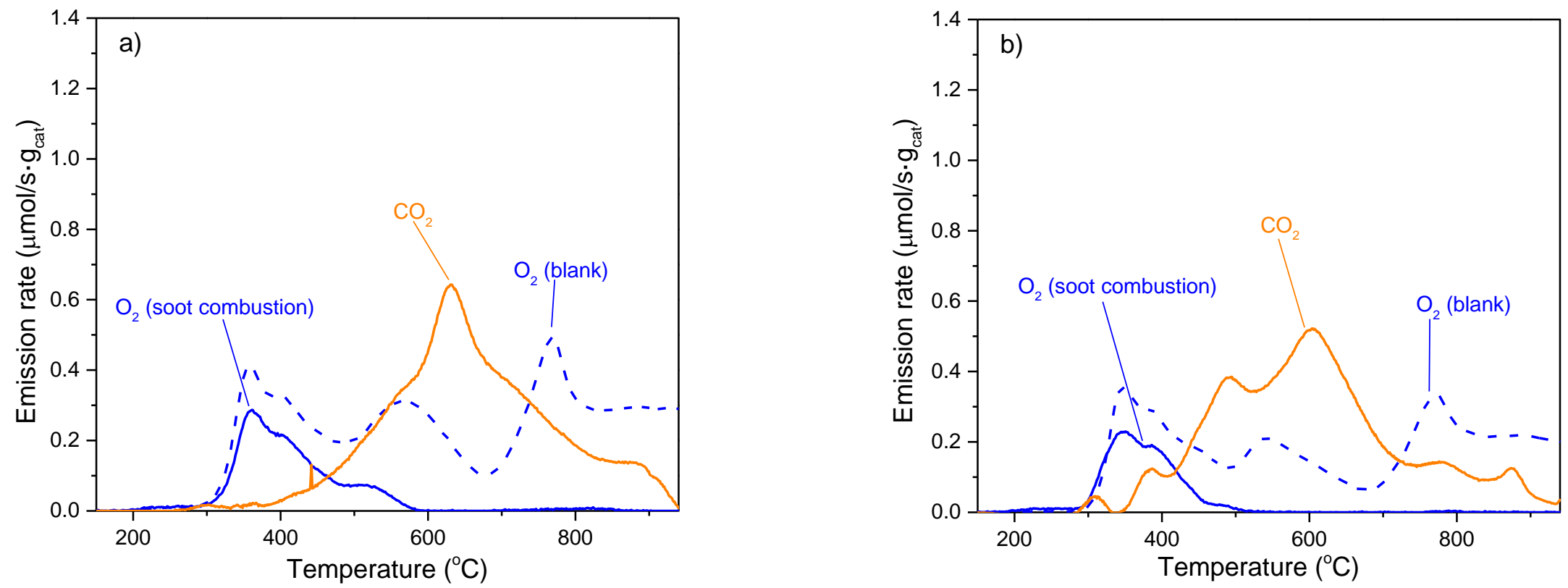

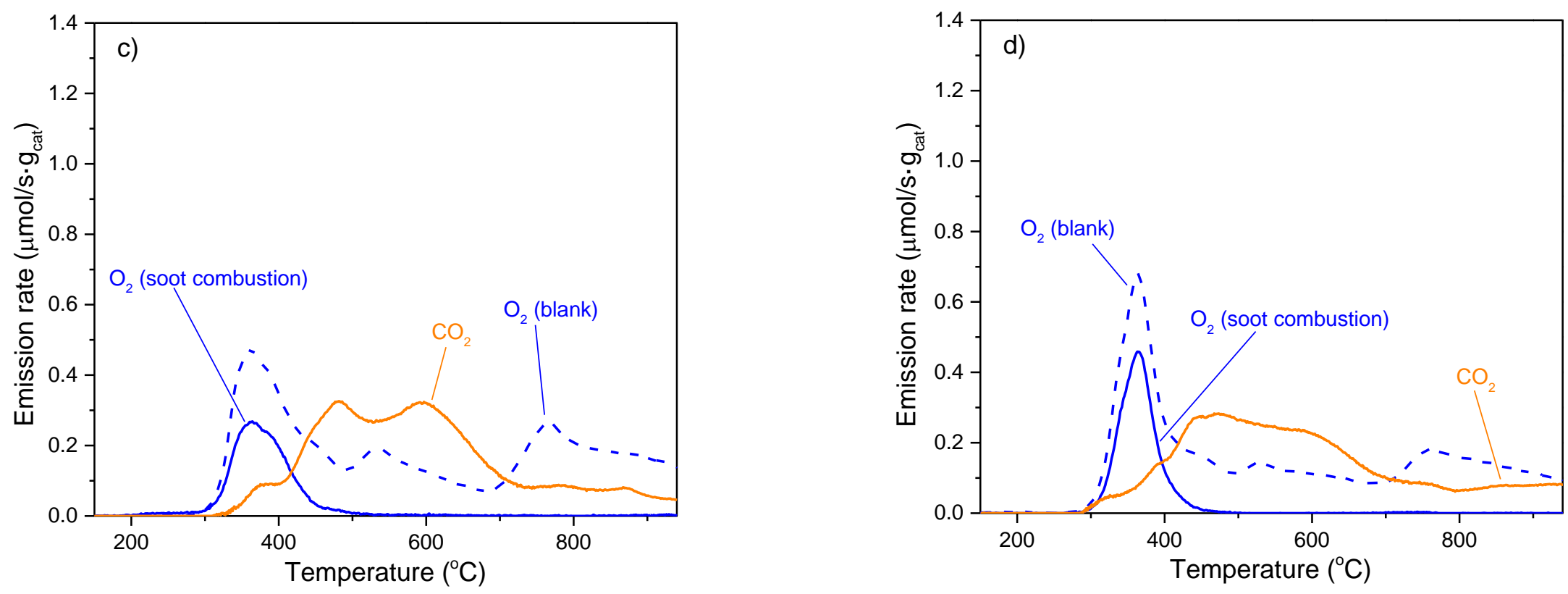

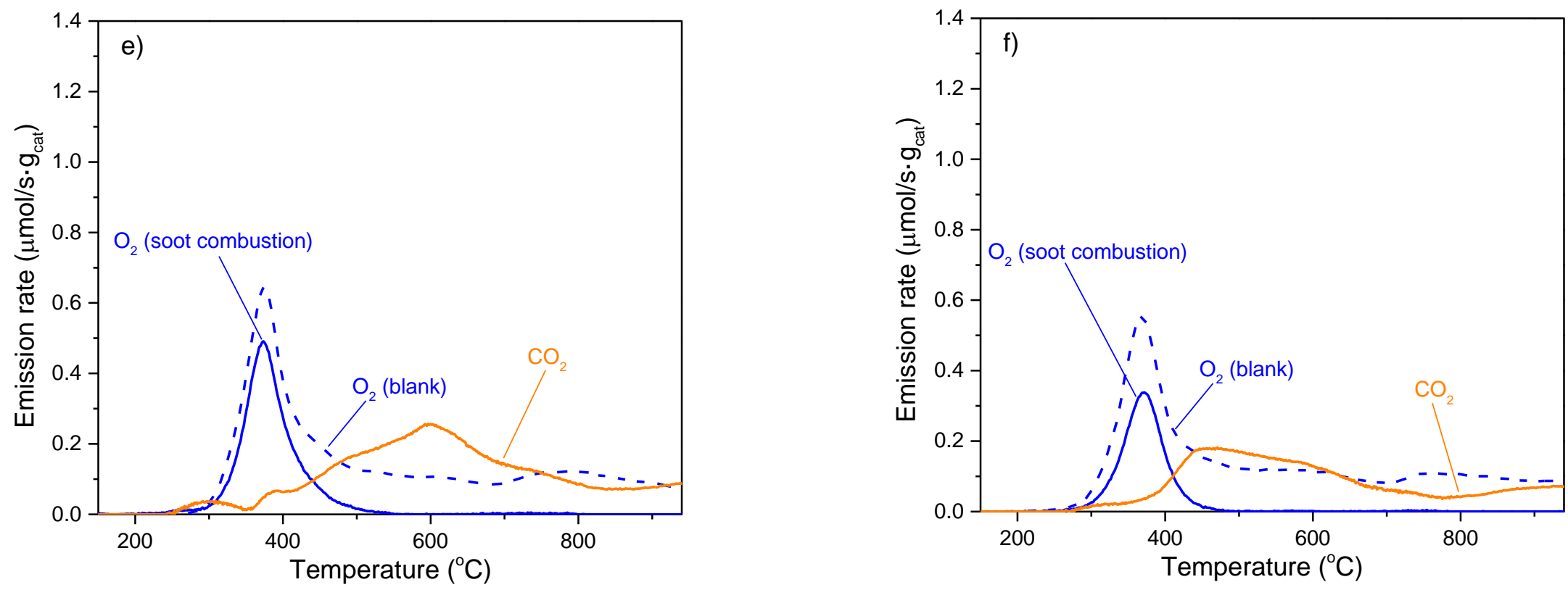

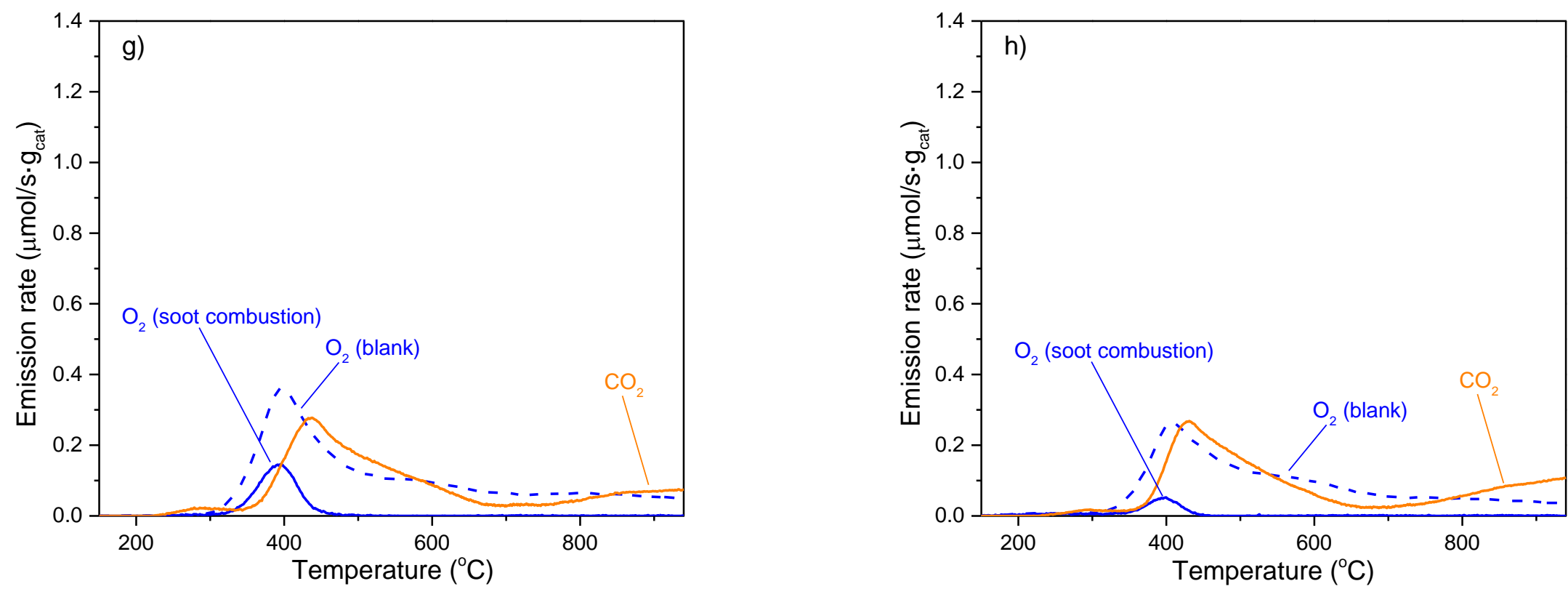

Fig. 11. $\mathrm{CO}_{2}$ and $\mathrm{O}_{2}$ emission profiles obtained during the soot combustion experiments under inert atmosphere in loose contact mode for direct calcination samples: a) $\operatorname{PrO}_{2}$; b) $\mathrm{Ce}_{0.1} \operatorname{Pr}_{0.9} \mathrm{O}_{2}$; c) $\mathrm{Ce}_{0.2} \operatorname{Pr}_{0.8} \mathrm{O}_{2}$; d) $\mathrm{Ce}_{0.3} \operatorname{Pr}_{0.7} \mathrm{O}_{2}$; e) $\mathrm{Ce}_{0.4} \operatorname{Pr}_{0.6} \mathrm{O}_{2} ;$ f) $\left.\mathrm{Ce}_{0.5} \operatorname{Pr}_{0.5} \mathrm{O}_{2} ; \mathrm{g}\right) \mathrm{Ce}_{0.6} \operatorname{Pr}_{0.4} \mathrm{O}_{2} ;$ and h) $\mathrm{Ce}_{0.7} \operatorname{Pr}_{0.3} \mathrm{O}_{2}$.

$\left(\mathrm{O}_{2}\right.$ emitted during the $\mathrm{O}_{2}$-TPD of the corresponding catalyst is represented in dotted line for comparison purpose). 

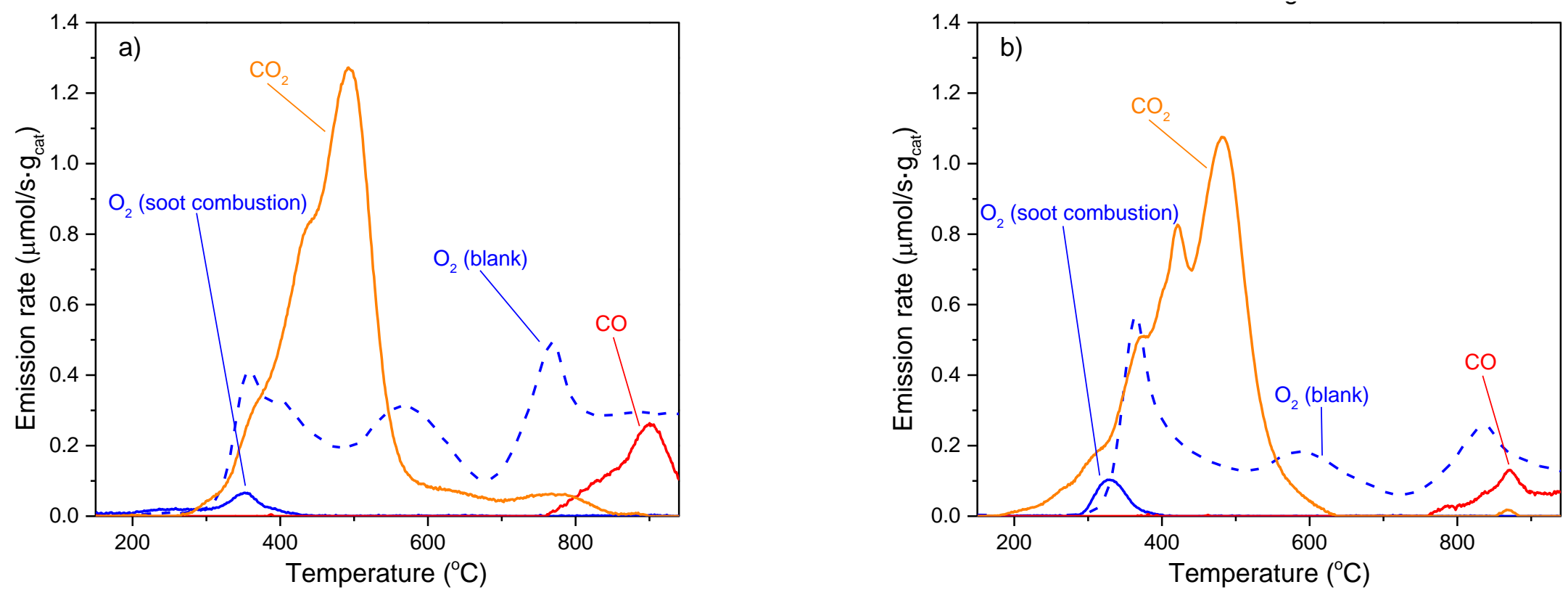

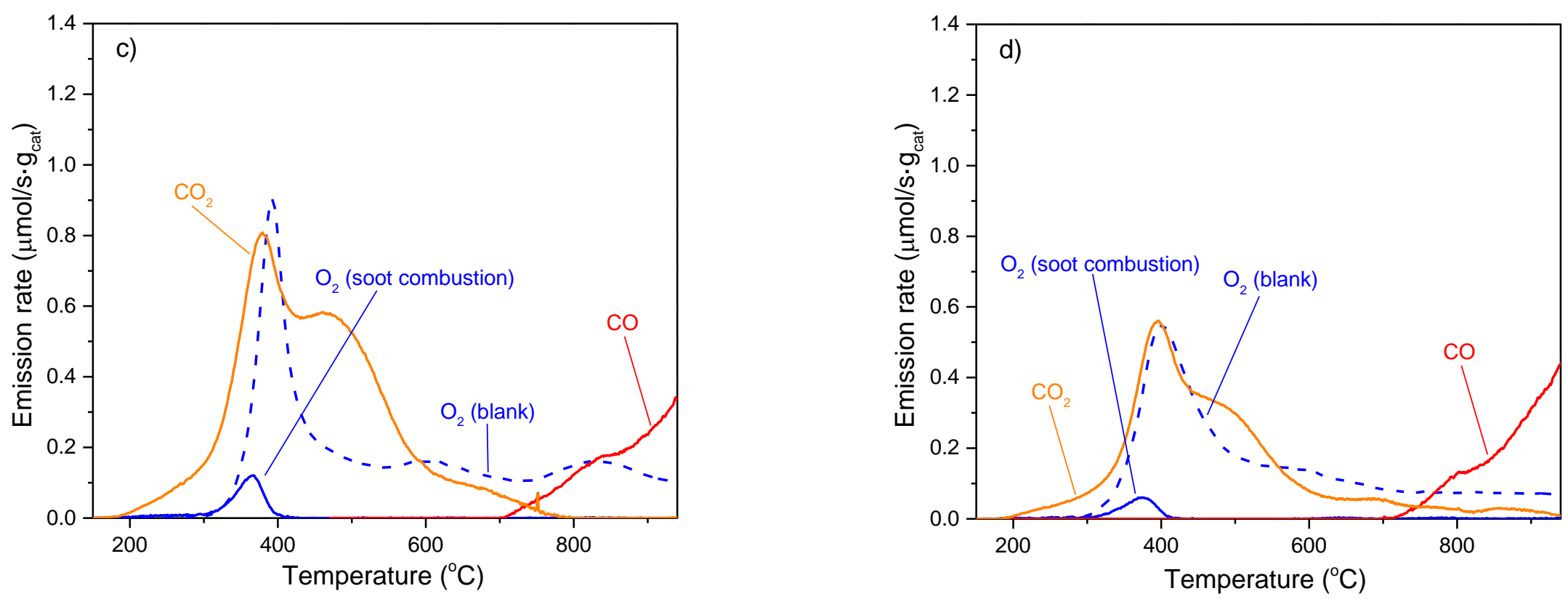

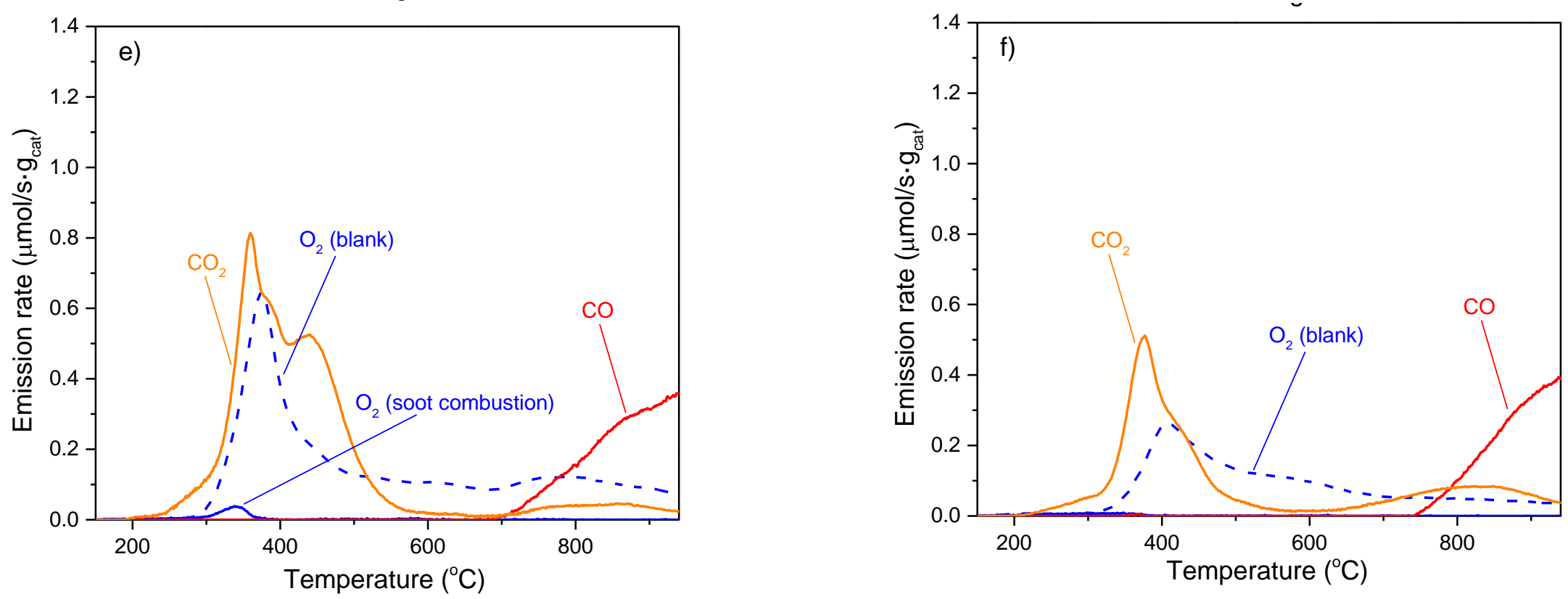

Fig. 12. $\mathrm{CO}_{2}, \mathrm{CO}$ and $\mathrm{O}_{2}$ emission profiles obtained during the soot combustion experiments under inert atmosphere in tight contact mode for: a) $\mathrm{PrO}_{2}-\mathrm{CN}$; b) $\mathrm{Ce}_{0.1} \operatorname{Pr}_{0.9} \mathrm{O}_{2}-\mathrm{CP}$; c) $\mathrm{Ce}_{0.2} \mathrm{Pr}_{0.8} \mathrm{O}_{2}-\mathrm{CP}$; d) $\mathrm{Ce}_{0.4} \operatorname{Pr}_{0.6} \mathrm{O}_{2}-\mathrm{CP}$; e) $\mathrm{Ce}_{0.4} \operatorname{Pr}_{0.6} \mathrm{O}_{2}-\mathrm{CN}$; and f) $\mathrm{Ce}_{0.7} \operatorname{Pr}_{0.3} \mathrm{O}_{2}-\mathrm{CN}$.

$\left(\mathrm{O}_{2}\right.$ emitted during the $\mathrm{O}_{2}$-TPD of the corresponding catalyst is represented in dotted line for comparison purpose). 


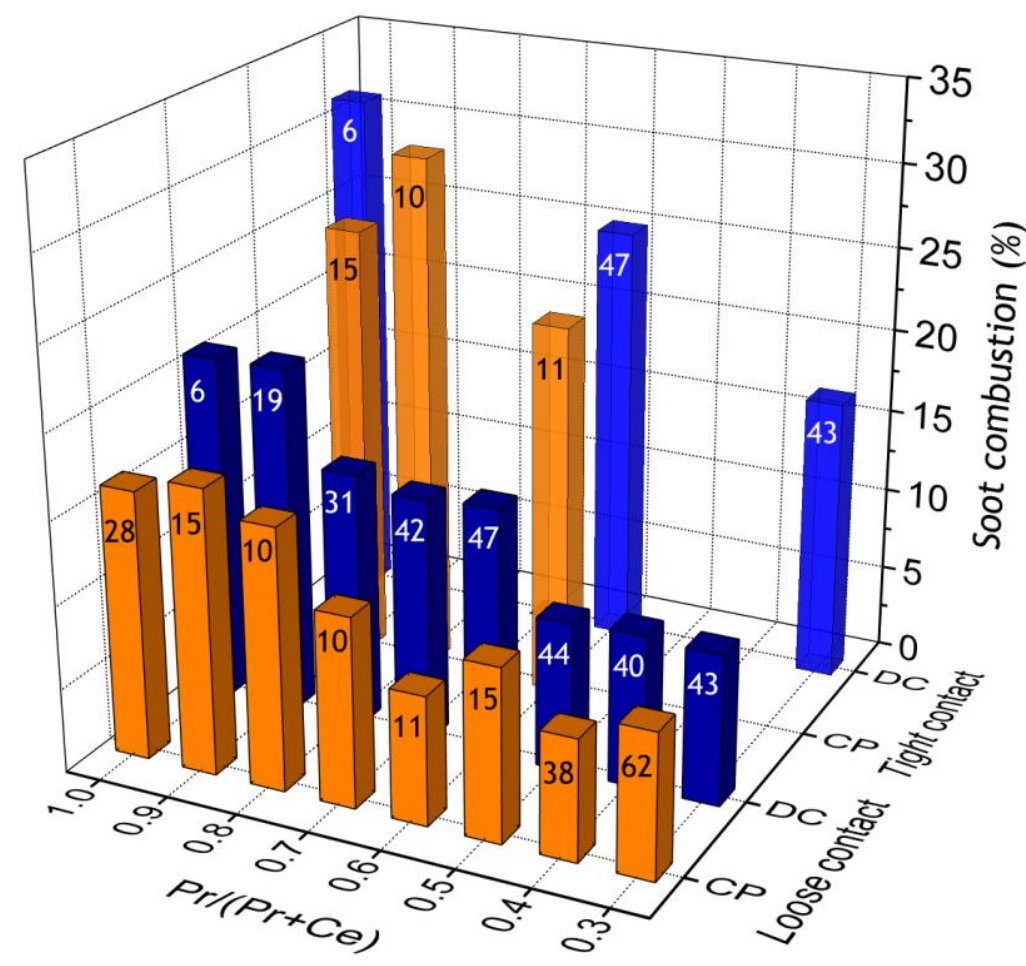

Fig. 13. Soot combustion (\%) under inert atmosphere for ceria-praseodymia oxides as function of Pr content for selected catalysts (numbers on bars reflect BET surface areas of the corresponding catalysts). 